\title{
Proteomic Profile of TGF- $\beta 1$ treated Lung Fibroblasts identifies Novel Markers of Activated Fibroblasts in the Silica Exposed Rat Lung
}

(1)

Mao $\mathrm{Na}^{1 *}$, Xu Hong2 ${ }^{2 *}$, Jin Fuyu ${ }^{1}$, Xu Dingjie ${ }^{3}$, Dominic Sales ${ }^{4}$, Zhang Hui ${ }^{1}$, Wei Zhongqiu ${ }^{1}, \mathrm{Li}$

Shifeng², Gao Xuemin², Cai Wenchen ${ }^{5}$, Li Dan¹, Zhang Guizhen", Zhang Bonan ${ }^{5}$, Zhang Lijuan², Li Shumin ${ }^{5}$, Zhu ying ${ }^{5}$, Wang Jin ${ }^{1}$, Rui Mingwang ${ }^{2}$, Ross Summer ${ }^{4}$, Yang Fang ${ }^{1,5 \#,}$

1. Basic Medical College, North China University of Science and Technology, Tangshan, China

2. Medical Research Center, North China University of Science and Technology, Tangshan, Chin a

3. College of Traditional Chinese Medicine, North China University of Science and Technology, Tangshan, China

4. Center for Translational Medicine, Jane and Leonard Korman Respiratory Institute, Thomas Jefferson University, Philadelphia, PA, USA

5. School of public health, North China University of Science and Technology, Tangshan, China (6)

$$
\text { *co-first author }
$$

\#corresponding author:

Fang Yang, M.D.

Basic Medical College, North China University of Science and Technology

No. 21 Bohai Road, Caofeidian Eco-city, Tangshan city, Hebei province 063000, China

Email: fangyang990404@sina.com 
ABSTRACT: We performed liquid chromatography-tandem mass spectrometry (LC-MS/MS) on control and TGF- $\beta 1$-exposed rat lung fibroblasts to identify proteins differentially expressed between cell populations. A total of 1648 proteins were found to be differentially expressed in response to TGF- $\beta 1$ treatment and 196 proteins were expressed at $\geq 1.2$ fold relative to control. Guided by these results, we next determined whether similar changes in protein expression were detectable in the rat lung after chronic exposure to silica dust. Of the five proteins selected for further analysis, we found that levels of all proteins were markedly increased in the silica-exposed rat lung, including the proteins for the very low density lipoprotein receptor (VLDLR) and the transmembrane (type I) heparin sulfate proteoglycan called syndecan 2 (SDC2). Because VLDLR and SDC2 have not, to our knowledge, been previously linked to the pathobiology of silicosis, we next examined whether knockdown of either gene altered responses to TGF- $\beta 1$ in MRC-5 lung fibroblasts. Interestingly, we found knockdown of either VLDLR or SDC2 dramatically reduced collagen production to TGF- $\beta 1$, suggesting that both proteins might play a novel role in myofibroblast biology and pathogenesis of silica-induced pulmonary fibrosis. In summary, our findings suggest that performing LC-MS/MS on TGF- $\beta 1$ stimulated lung fibroblasts can uncover novel molecular targets of activated myofibroblasts in silica-exposed lung.

Key words: proteomics; fibroblast; silicosis; lung; pulmonary fibrosis 


\section{Highlights:}

50 We identified 196 proteins differentially expressed between control and TGF- $\beta 1$ 51 treated fibroblastsby LC-MS/MS.

52 Several proteins identified by LC-MS/MS were also found to be differentially 53 expressed in whole lung tissues and isolated fibroblasts after chronic exposure to 54 silica dust, including the very low density lipoprotein receptor (VLDLR) and the transmembrane type I heparan sulfate proteoglycan called syndecan 2

56 Knockdown of SDC2 or VLDLR markedly inhibited collagen production in MRC-5

57 fibroblasts, suggesting a novel pathogenic role for these proteins in myofibroblast biology. 
Silicosis is a highly prevalent occupational condition that is caused by chronic inhalation of crystalline silica particulates (aerodynamic diameter $<5 \mu \mathrm{m}$ ) into the distal air spaces of the lung. Though this disease is largely preventable by implementing strict safety and health standards at work, silicosis remains one of the more common occupational disorders in many parts of the world, including China.

Although silica dust has been shown to injure many cell types in the lung it is generally believed that activated myofibroblasts play a central role in driving the development of disease. Central to this activation is signaling through the transforming growth factor $\beta 1$ (TGF- $\beta 1$ ) receptor, which leads to a cascade of events that trigger the transdifferentation of fibroblasts to myofibroblasts and induce the production of large quantities of collagen and other extracellular matrix materials (Gauldie et al., 1999; Harris et al., 2013; Jagirdar et al., 1996). Despite decades of work on TGF- $\beta 1$ signaling in lung fibroblasts much remains to be learned about molecular mechanisms controlling myofibroblast growth and activation. Moreover, it is largely believed by many experts in the field that gaining additional insight into biological events downstream of TGF- $\beta 1$ signaling could lead to the identification of new molecular targets for the treatment of silicosis and various other fibrotic lung conditions.

In our previous work, we utilized a 2-DE proteomic approach to identify novel biomarkers of silicosis (Xiaojun et al., 2016). However, it is now clear that using isobaric tags for relative quantification (iTRAQ) has several advances over the 2-DE approach including higher throughput quantification, decreased analytical time, and lower run-to-run variation (Rauniyar et al., 2014). With this in mind, the objective of this work was to utilize iTRAQ coupled liquid chromatography-tandem mass spectrometry (LC-MS/MS) to identify novel markers of activated rat lung fibroblasts and to utilize this information to assess whether similar markers were upregulated in the rat lung after chronic exposure to silica dust. 


\section{MATERIALS AND METHODS}

Cell culture. Rat lung fibroblasts were isolated from 1-3 day old Wistar rats as previously described (Xu et al., 2012). Briefly, freshly isolated cells were culture for 3 to 4 passages and then transferred to low serum conditions (0.5\% FBS) for $24 \mathrm{~h}$. Following serum deprivation, cellwere treated with 5 ng/ml TGF- $\beta 1$ (240-B; R\&D Systems, Inc., Minneapolis, MN, USA) or vehicle controlfor $24 \mathrm{~h}$ and whole cell lysates were collected for later analysis (Xiaojun, et al., 2016). For each group, cells from 10 independent samples were pooled for proteomics analysis.

Fibroblasts used in our studies were derived from the lungs of control and silica-exposed rats(Seluanov et al., 2010) and the MRC-5 cell line. Fibroblasts were cultured in MEM containing 2\% HEPES, 1\% nonessential amino acid, and 10\% FBS. Transient transfections were carried out using lipofectamine 2000 (Invitrogen, USA) according to the manufacturer's recommendations. Knockdown was performed by exposing MRC-5 cells to $10 \mathrm{ng}$ of siRNA targeting either very low-density lipoprotein receptor (VLDLR) or syndecan-2 (SDC2). Six hours after transfection, cells were washed and exposed to medium containing vehicle control or TGF- $\beta 1$.

siRNAs used in our studies were derived from following sequences: 1) VLDL R-siRNA 1: GUGCAACAAUGGCCAGUGU dTdT; CACGUUGUUACCGGUCA CA dTdT; 2) VLDLR-siRNA 2: GCGAGUGCAUCCAUAAGAA dTdT; CGCU CACGUAGGUAUUCUU dTdT; 3) VLDLR-siRNA 3: GAUCGACAAUGUCUA UAAU dTdT; CUAGCUGUUACAGAUAUUA dTdT; 4) SDC2-siRNA 1: CCA CGACGCUGAAUAUACA dTdT; GgUGCUGCGACUUAUAUGU dTdT; 5) SD C2-siRNA 2: GUUGGUGUAUCGCAUGAGA dTdT; CAACCACAUAGCGUAC UCU dTdT; 6) SDC2-siRNA 3: GGAGAACGCAAACCAUCCA dTdT; CCUCU UGCGUUUGGUAGGU dTdT.

Sample preparation for LC-MS/MS analysis. Proteins for LC-MS/MS were as prepared previously described (Wisniewski et al., 2009)(Promega, Fitchburg, Wisconsin, USA). Briefly, cell lysates were loaded onto a 10-kDa filter unit (Pall Corp., Port Washington, New York, USA), and filter was sequentially washed with 
UA (8 $\mathrm{M}$ urea in $0.1 \mathrm{M}$ Tris- $\mathrm{HCl} ; \mathrm{pH} 8.5)$ and $\mathrm{ABC}\left(25 \mathrm{mMNH}_{4} \mathrm{HCO}_{3}\right)$ buffers.

Proteins in collected samples were then denatured in $20 \mathrm{mM}$ DTT at $50^{\circ} \mathrm{C}$ for $1 \mathrm{~h}$ and carboxyamidomethylated with $50 \mathrm{mM}$ iodoacetamide (IAA) for $45 \mathrm{~min}$. This step was followed by a digestion step using Trypsin Gold (1:50) at $37^{\circ} \mathrm{C}$ overnight. Peptide fragments were next desalted using Oasis HLB cartridges (Waters, Milford, Massachusetts, USA), dried by vacuum centrifugation (Thermo Fisher Scientific, Bremen, Germany) and again collected as a filtrate. Finally, samples were labelled with 4-plex iTRAQ reagent (AB Sciex) according to the manufacture's protocol, with the control group labelled with tag 116 and TGF- $\beta$ group with tag 117.

High-performance liquid chromatography (HPLC) separation. Pooled mixtures of labelled samples were fractionated using a high-pH HPLC on a Waters Xbridge C18 column $(4.6 \mathrm{~mm} \times 250 \mathrm{~mm}, 3 \mu \mathrm{m})$. Samples were loaded onto a column equilibrated in buffer $\mathrm{A} 1\left(\mathrm{H}_{2} \mathrm{O} ; \mathrm{pH} 10\right)$, with an elution gradient of $5-25 \%$ buffer B1 $(90 \%$ ACN; $\mathrm{pH} 10)$ and a flow rate $=1 \mathrm{~mL} / \mathrm{min}$ for $60 \mathrm{~min}$. Flow-through was collected at 1 minute intervals for a total of 60 fractions. Solutions were then dried, re-suspended in $0.1 \%$ formic acid, and pooled by concatenating fractions 1,$31 ; 2,32$; and so on. Analyses were performed on just odd number fractions.

LC-MS/MSanalysis. Each fraction was analysed with a reverse-phase-C18 self-packed capillary LC column $(75 \mu \mathrm{m} \times 100 \mathrm{~mm})$, with an elution gradient of $5 \%-$ $30 \%$ buffer B2 $(0.1 \%$ formic acid, $99.9 \% \mathrm{ACN}$; flow rate $=0.3 \mu \mathrm{L} / \mathrm{min})$ for $40 \mathrm{~min}$. A Triple TOF 5600 mass spectrometer was used to analyze the eluted peptides, with each fraction run in duplicate. The MS data were acquired using the high-sensitivity mode with the following parameters: 30 data-dependent MS/MS scans per full scan; full scans acquired at a resolution of 40,000 and MS/MS scans at a resolution of 20,000; rolling collision energy, charge state screening (including precursors with a charge state of +2 to +4 ), and dynamic exclusion (exclusion duration $15 \mathrm{~s}$ ); and a MS/MS scan range of $100-1800 \mathrm{~m} / \mathrm{z}$, with a scan time of $100 \mathrm{~ms}$.

Date analysis. Data acquired from LC-MS/MS were analysed using the Mascot software (version 2.4.1, Matrix Science, London, UK). Proteins were identified by 
searching peptide spectral matches against the Swissprot_2014_07 database (taxonomy: Rattus, containing 7,906 sequences). The parameters utilized included trypsin as the digestion enzyme, two or fewer missed cleavage sites and cysteine carbamidomethylation (57.02146) as a fixed modification. The precursor ion mass tolerance and the fragment ion mass tolerance were set to ppm and $0.05 \mathrm{Da}$ respectively. Protein identifications from Mascot were validated using the Scaffold Proteome Software (version 4.3.3, Proteome Software Inc., Portland, OR). Peptide identifications were accepted if false discovery rate (FDR) was less than $1.0 \%$ and if at least 2 unique peptides were identified from the same protein. iTRAQ, Scaffold Q+ was used for Label Based Quantification (TMT, iTRAQ, SILAC, etc.) of peptides and proteins. For each channel, the acquired reporter ion intensities were normalized by the sum of all reporter ion intensities of that channel. Normalized intensities were then used to calculate the relative protein abundance and quantify protein ratios(Nesvizhskii et al., 2003). Proteins identified from these analyses were further analysed to determine function, ontology and location using the PANTHER classification system (Protein Analysis Through Evolutionary Relationships; http://www.pantherdb.org/) (Mi et al., 2013).

Silicosis model. Male Wistar rats were purchased from Vital River Laboratory Animal Technology Co. Ltd. (SCXY 2009-0004; Beijing, China) and all experiments were performed in accordance with the regulations set by the Committee on the Ethics of North China University of Science and Technology. Silica dust was delivered to rats using a HOPE MED 8050 exposure control apparatus (HOPE Industry and Trade Co. Ltd, Tianjin, China) with the $\mathrm{SiO}_{2}(\mathrm{~s} 5631$, Sigma-Aldrich, St. Louis, MO, USA) concentration maintained at 2,000 mg/m³ (Liu et al., 2017). At experimental endpoints, bronchoalveolar lavage was performed with $0.9 \%$ saline and whole lung tissues were then snap-frozen in liquid nitrogen.

Immunohistochemistry (IHC).Paraffin-embedded tissue sections were used for IHC. Endogenous peroxidases were quenched with $3 \% \mathrm{H}_{2} \mathrm{O}_{2}$ and antigen retrieval was performed using a high-pressure method with deparaffinised sections. The samples 
175 were then incubated with primary antibodies against collagen V(COL V, A1515, 176 ABclonal Biotech, Wuhan, China), collagen XI (COL XI, DF3553, Affinity 177 Biosciences, Cincinnati, OH, USA), VLDLR (TA309928, OriGene Technologies, 178 Rockville, MD, USA) or SDC2 (A1810, ABclonal Biotech, Wuhan, China) at $4^{\circ} \mathrm{C}$ overnight. The following morning, tissue sections were incubated with secondary antibody conjugated with the horseradish peroxidase enzyme (PV-6000; Beijing ZhongshanJinqiao Biotechnology Co. Ltd, China) at $37^{\circ} \mathrm{C}$ for $20 \mathrm{~min}$. Immunoreactivity was visualised with using the DAB substrate (ZLI-9018; ZSGB-BIO, Beijing, China) and the nuclei were stained with hematoxylin.

Western blot analysis. Total protein levels were quantified using a Bradford assay (PC0020; Solarbio, China) as previously described. Protein lysates (20 $\mu \mathrm{g} / \mathrm{lane})$ were separated on a $13 \%$ gel by SDS-PAGE and were electro-transferred onto polyvinylidene fluoride (PVDF) membranes (Amervehicle Biosciences). The membranes were blocked with 5\% non-fat milk and incubated with primary antibodies against COL V, COL XI, Vascular cell adhesion protein (VCAM, ab134047, Abcam, Cambridge, MA, USA), Transmembrane protein 214 (TM214, TS306822, OriGene Technologies, Rockville, MD, USA), VLDLR, SDC-2 or $\alpha$-SMA at $4{ }^{\circ} \mathrm{C}$ overnight. Membranes were next washed in TBST and incubated with peroxidase-labelled affinity-purified anti-rabbit/mouse $\operatorname{IgG}(\mathrm{H}+\mathrm{L})$ secondary antibody(074-1506/074-1806;Kirkegard and Perry Laboratories). Protein bands were visualised using ECL ${ }^{\mathrm{TM}}$ Prime Western Blotting Detection Reagent (RPN2232; GE Healthcare, Hong Kong, China) and expressed as a fold change relative to $\alpha$-Tubulin (Tub $\alpha$, AF7010; Affinity Biosciences, Cincinnati, OH, USA).

Statistical analysis. Comparisons between two groups were performed using independent sample $t$-test. Comparisons between multiple independent groups were done using a one-way ANOVA followed by a post-hoc analysis with the Bonferroni test. Values were expressed as a means \pm Std, with p-values less than 0.05 considered as statistically significant. 


\section{RESULTS}

205

206

Proteomic profile differs between control and TGF- $\beta 1$ lung fibroblasts. To identify proteins differentially expressed between control and activated fibroblasts, we performed iTRAQ coupled with LC-MS/MS on rat lung fibroblasts treated with or without TGF- $\beta 1$ for $24 \mathrm{~h}$. Using scaffold integration, we observed a total of 1648 proteins differentially expressed between control and TGF- $\beta 1$ treated cells. Moreover, 196 of these proteins were expressed at $\geq 1.2$ fold-change (Tables S1 and S2) and 20 proteins exhibited $\mathrm{a} \geq 1.5$ fold-change (Table 1) relative to control.

\section{Bioinformatic analyses of differentially expressed proteins in control and TGF- $\beta 1$} stimulated lung fibroblasts. Proteins whose expression changed most significantly after exposure to TGF- $\beta 1$ were classified into functional classes using the PANTHER analysis. Gene ontology (GO) analysis classified proteins into three distinct categories entitled: 1) molecular function; 2) biological process; and 3) components of the cell. Among these categories most proteins were belonged to molecular functions group (Table S3), and the major subgroups within this category included: 1) catalytic activity $(40 \%)$; 2) protein binding (26\%), and 3) structural activity (20\%). In the biological processes category (Table S4), most proteins belonged to the subgroups: 1) cellular process $(26 \%)$; 2) metabolic process $(22 \%)$, or 3) cellular component/biogenesis (10\%) subgroup; and proteins within the components of a cell group belonged to 1) cell part $(40 \%) ; 2)$ cellular organelle $(25 \%)$; and 3) macromolecular complexes (18\%) (Table S5).

Within PANTHER, class ontology was also performed (Table S6), with the largest number of proteins assigned to the following categories:1) nucleic acid binding (18\%); 2) hydrolase (10\%); 3) enzyme modulator and transferase (each 7\%); 4) cytoskeletal protein $(6 \%) ; 5)$ signalling molecule $(6 \%)$; and 7) transfer/carrier protein $(6 \%)$. Pathway analysis showed that all proteins that were differentially expressed in response to TGF- $\beta 1$ fell into one of the following signalling pathways: 1 ) integrin; 2) angiogenesis; 3) CCKR; 4)conadotropin-releasing hormone receptor; 5) p53; 6) Alzheimer disease-presenilin; 7) blood coagulation; 8) cadherin; 9) cholesterol 
biosynthesis; 10) FGF or 11) Wntsignalling pathways (Table S7).

Proteinsincreased in TGF- $\beta 1$ stimulated lung fibroblasts were also increased in

the silica-exposed rat lung. To determine whether in vitro findings were representative of changes in vivo, we next performed IHC and western blot analysis on control and silica-exposed lung tissues for those proteins whose expression changed most significantly ( $\geq 1.5$ fold increase) in response to TGF- $\beta 1$ treatment. However, our analysis was limited to proteins in which a commercially available antibody for IHC or WB was available; this included the proteins COLV, COL XI, VCAM1, TM214, VLDLR, and SDC2 for protein identification.

As shown in Figure 1A, van Gieson (VG) staining confirmed the ability of our model to induce severe fibrotic responses in the rat lung as demonstrated by an increase in extracellular matrix deposition and the large number of silicotic nodules. Western blot analysis also showed an increase in COLI and $\alpha$-SMA in whole lung tissues and primary lung fibroblasts after silica exposure (Figure 1B).

As shown in Figure 2, Western blot analysis revealed a marked increase in the expression of COL V, COL XI, and VCAM1 in the lungs of silica exposed rats, including whole lung tissues and freshly isolated lung fibroblasts. Moreover, IHC staining of the lung showed the elevated levels of COL V and COL XI was confined mostly to the interstitium of the lung, particularly in areas with evidence of active inflammation and fibrosis. Despite multiple attempts, staining for VCAM1 was detected in either the control or the silica-exposed rat lung, indicating that our antibody could not be used for IHC.

255 In addition to the above proteins, we found that levels of VLDLR and SDC2 were 256 also markedly increased by western blot in whole lung tissues and isolated fibroblasts 257 after silica exposure. (Figure 3). Significant increases in VLDLR and SDC2 expression were also observed by IHC in the silica-exposed lung. 
261 COL V and COL XL) and VCAM expression(Agassandian et al., 2015) were

262 increased in fibrotic lung tissues we were intrigued by the observation that levels of

263 VLDLR and SDC2 were also markedly elevated in the lung after silica exposure.

264 Even after an exhaustive search, we were unable to find any reports linking either

265 VLDLR or SDC2 to silicosis in any tissues. Based on this, we speculated whether

266 changes in the expression of VLDLR or SDC2 can influence fibrotic responses to

267 TGF $\beta 1$ in lung fibroblasts. To test this, we next performed siRNA knockdown of

268 VLDLR or SDC2 in MRC-5 cells using several different siRNA probes. Because the

269 quantity of gene knockdown varied with different siRNAs we utilized only siRNAs

270 demonstrating the most effective knockdown in our studies; this was siRNA 2 and 3

271 for VLDLR, and siRNA 3 for SDC2 (Figure 4). As shown in Figure 4, we found that

272 knockdown of VLDLR markedly reduced COL I and $\alpha$-SMA expression in TGF $\beta 1$

273 treated MRC-5 fibroblasts. Moreover, we also found that knockdown of SDC2

274 significantly suppressed COLI expression, although non-significant decreases in $275 \alpha$-SMA levels were seen in TGF $\beta 1$ treated cells. 


\section{DISCUSSION}

Biomarker discovery can be accomplished using a variety of proteomic approaches and biological specimens, including urine, serum or lysates from whole organ digests. However, for research in solid organs, such as the heart, brain, kidney or lung, it is often difficult to obtain sufficient quantities of patient samples for proteomic work. Moreover, tissue lysates, are composed of a conglomeration of different cell types, such as epithelial cells, smooth muscle cells, fibroblasts, immune cells and endothelialium, making it difficult to uncover novel biological mechanisms in individual cell types. Thus, in vitro models of individual cell populations are often employed to identify novel candidate biomarkers of functional processes in vivo (Paul et al., 2013).

In this study, we performed iTRAQ-coupled LC-MS/MS analysis on rat lung fibroblasts treated with or without TGF- $\beta 1$ to identify novel markers of activated myofibroblasts in the silica-exposed lung. From these studies, we identified many proteins differentially expressed and 196 proteins expressed at $\geq 1.2$ fold relative to control. Importantly, many of these proteins were novel markers and had not previously been linked to TGF- $\beta 1$ signalling in the lung, including several whose functional classes have been intimately tied to myofibroblast activation such as integrin and angiogenesis pathways as well as those less clearly associated with myofibroblast biology such as nucleic acid binding, hydrolase activity and transferase activity.

An important finding in this study was the observation that some of the proteins we identified in our proteomics analyses were also differentially expressed in the lung after silica exposure. For example, we found that levels of COL XI and COL V were markedly increased in the silicotic lung, although these findings were not surprising given the fact that collagen production is a well-recognized by product of TGF- $\beta 1$ signalling(Raglow et al., 2015). However, we also found that VCAM were significantly increased in the lung after silica exposure. The former findings is also 
not unexpected given that transcript and protein levels of VCAM are reported to be increased in fibroblastic foci of IPF lungs (Agassandian, et al., 2015).

Two other proteins found to be differentially expressed in our proteomic analyses were VLDLR and SDC2. We were intrigued by these observations because our review of the literature had not previously associated these proteins with silicosis. Western blot analysis and IHC confirmed that both proteins were increased in whole lung tissues and isolated fibroblasts from the lungs of silica-exposed rats. Interestingly, VLDLR expression is known to be increased in the fibrotic caps of atherosclerotic lesions in systemic blood vessels, suggesting it may be involved in more than just lipid trafficking (Eck et al., 2005). In IPF patient lung tissues, SDC2 was found to be over-expressed in two reports (Chen et al., 2004; Ruiz et al., 2012). More importantly, we found that knocking down the expression of either VLDLR or SDC2 effectively reduced collagen production, supporting the notion that these proteins play a role in the pathobiology of pulmonary fibrosis.

In conclusion, iTRAQ coupled LC-MS/MS of TGF- $\beta 1$-induced fibroblasts can be utilized to identify novel markers of silica-induced lung fibrosis. Future mechanistic studies will be needed to uncover whether individual proteins are simply a marker of disease or play a biological role in the onset or progression of pulmonary fibrosis. 


\section{Ethics approval}

All animal experiments were reviewed and approved by the Institutional Animal Care and Use Committee at the North China University of Science and Technology University prior to the initiation of any studies.

\section{Consent for publication}

Not applicable.

\section{Competing interests}

The authors declare that they have no competing interests.

\section{Funding}

This work was supported by the National Natural Science Foundation of China (No. 81472953); the Natural Science Foundation of Hebei Province (No. H20162091705); and Outstanding Young Foundation of North China University of Science and Technology (JP201513).

Authors' contributions

FY and HX designed the study. MN, JF, ZH, XD, YY, MN, GX, and GY carried out the experimental work, analyzed the data, and drafted the manuscript. RS participated in the design of the study and critically reviewed the manuscript and provided intellectual input. RS and RM helped write and critically reviewed the manuscript and provided intellectual input. WZ, ZB, LS, LS and WJ conceived the study, and participated in coordination, and helped in drafting the manuscript. All authors read and approved the final manuscript.

\section{Acknowledgements}

Not applicable. 


\section{REFERENCES}

Agassandian, M., Tedrow, J. R., Sembrat, J., Kass, D. J., Zhang, Y., Goncharova, E. A., Kaminski, N., Mallampalli, R. K., and Vuga, L. J. (2015). VCAM-1 is a TGF-beta1 inducible gene upregulated in idiopathic pulmonary fibrosis. Cellular signalling 27(12), 2467-73.

Chen, L., Klass, C., and Woods, A. (2004). Syndecan-2 regulates transforming growth factor-beta signaling. The Journal of biological chemistry 279(16), 15715-8.

Eck, M. V., Oost, J., Goudriaan, J. R., Hoekstra, M., Hildebrand, R. B., Bos, I. S., van Dijk, K. W., and Van Berkel, T. J. (2005). Role of the macrophage very-low-density lipoprotein receptor in atherosclerotic lesion development. Atherosclerosis 183(2), 230-7.

Gauldie, J., Sime, P. J., Xing, Z., Marr, B., and Tremblay, G. M. (1999). Transforming growth factor-beta gene transfer to the lung induces myofibroblast presence and pulmonary fibrosis. Current topics in pathology. Ergebnisse der Pathologie 93, 35-45.

Harris, W. T., Kelly, D. R., Zhou, Y., Wang, D., MacEwen, M., Hagood, J. S., Clancy, J. P., Ambalavanan, N., and Sorscher, E. J. (2013). Myofibroblast differentiation and enhanced TGF-B signaling in cystic fibrosis lung disease. PloS one 8(8), e70196.

Jagirdar, J., Begin, R., Dufresne, A., Goswami, S., Lee, T. C., and Rom, W. N. (1996). Transforming growth factor-beta (TGF-beta) in silicosis. American journal of respiratory and critical care medicine 154(4 Pt 1), 1076-81.

Liu, Y., Xu, H., Geng, Y., Xu, D., Zhang, L., Yang, Y., Wei, Z., Zhang, B., Li, S., Gao, X., et al. (2017). Dibutyryl-cAMP attenuates pulmonary fibrosis by blocking myofibroblast differentiation via PKA/CREB/CBP signaling in rats with silicosis. Respiratory research 18(1), 38.

Mi, H., Muruganujan, A., Casagrande, J. T., and Thomas, P. D. (2013). Large-scale gene function analysis with the PANTHER classification system. Nature protocols 8(8), 1551-66.

Nesvizhskii, A. I., Keller, A., Kolker, E., and Aebersold, R. (2003). A statistical model for identifying proteins by tandem mass spectrometry. Analytical chemistry 75(17), 4646-58.

Paul, D., Kumar, A., Gajbhiye, A., Santra, M. K., and Srikanth, R. (2013). Mass spectrometry-based proteomics in molecular diagnostics: discovery of cancer biomarkers using tissue culture. BioMed research international 2013, 783131.

Raglow, Z., and Thomas, S. M. (2015). Tumor matrix protein collagen XIalpha1 in cancer. Cancer 
letters 357(2), 448-53.

Rauniyar, N., and Yates, J. R., 3rd (2014). Isobaric labeling-based relative quantification in shotgun proteomics. Journal of proteome research 13(12), 5293-309.

Ruiz, X. D., Mlakar, L. R., Yamaguchi, Y., Su, Y., Larregina, A. T., Pilewski, J. M., and Feghali-Bostwick, C. A. (2012). Syndecan-2 is a novel target of insulin-like growth factor binding protein-3 and is over-expressed in fibrosis. PloS one 7(8), e43049.

Seluanov, A., Vaidya, A., and Gorbunova, V. (2010). Establishing primary adult fibroblast cultures from rodents. Journal of visualized experiments : JoVE doi: 10.3791/2033(44).

Wisniewski, J. R., Zougman, A., Nagaraj, N., and Mann, M. (2009). Universal sample preparation method for proteome analysis. Nature methods 6(5), 359-62.

Xiaojun, W., Yan, L., Hong, X., Xianghong, Z., Shifeng, L., Dingjie, X., Xuemin, G., Lijuan, Z., Bonan, Z., Zhongqiu, W., et al. (2016). Acetylated alpha-Tubulin Regulated by N-Acetyl-Seryl-Aspartyl-Lysyl-Proline(Ac-SDKP) Exerts the Anti-fibrotic Effect in Rat Lung Fibrosis Induced by Silica. Scientific reports 6, 32257.

Xu, H., Yang, F., Sun, Y., Yuan, Y., Cheng, H., Wei, Z., Li, S., Cheng, T., Brann, D., and Wang, R. (2012). A new antifibrotic target of Ac-SDKP: inhibition of myofibroblast differentiation in rat lung with silicosis. PloS one 7(7), e40301. 
Table 1. Subset of differentially expressed proteins in cultured TGF- $\beta$-induced

myofibroblasts relative to the untreated control

\begin{tabular}{lllcc}
\hline No. & Protein name & $\begin{array}{l}\text { Accession } \\
\text { Number }\end{array}$ & $\begin{array}{c}\text { Molecula } \\
\text { r Weight }\end{array}$ & $\begin{array}{c}\text { Fold } \\
\text { change }\end{array}$ \\
\hline 1 & Collagen alpha-1(II) chain & CO2A1_RAT & $135 \mathrm{kDa}$ & 1.60 \\
2 & Cluster of Histone H2A type 1 & H2A1_RAT [4] & $14 \mathrm{kDa}$ & 1.70 \\
3 & Collagen alpha-1(V) chain & CO5A1_RAT & $184 \mathrm{kDa}$ & 1.50 \\
4 & Protein S100-A11 & S10AB_RAT & $11 \mathrm{kDa}$ & 1.59 \\
5 & Vascular cell adhesion protein 1 & VCAM1_RAT & $81 \mathrm{kDa}$ & 1.55 \\
6 & Collagen alpha-1(XI) chain & COBA1_RAT & $181 \mathrm{kDa}$ & 1.70 \\
7 & Cluster of Thymosin beta-4 & TYB4_RAT & $5 \mathrm{kDa}$ & 2.50 \\
8 & Cluster of Haemoglobin subunit beta-1 & HBB1_RAT [2] & $16 \mathrm{kDa}$ & 2.25 \\
9 & Haemoglobin subunit alpha-1/2 & HBA_RAT & $15 \mathrm{kDa}$ & 1.90 \\
10 & Oxidised low-density lipoprotein receptor 1 & OLR1_RAT & $42 \mathrm{kDa}$ & 1.55 \\
11 & Transmembrane protein 214 & TM214_RAT & $77 \mathrm{kDa}$ & 1.50 \\
12 & Very low-density lipoprotein receptor & VLDLR_RAT & $97 \mathrm{kDa}$ & 1.55 \\
13 & Syndecan-2 & SDC2_RAT & $22 \mathrm{kDa}$ & 1.90 \\
14 & Serum albumin & ALBU_RAT & $69 \mathrm{kDa}$ & 0.59 \\
15 & Histone H4 & H4_RAT & $11 \mathrm{kDa}$ & 0.25 \\
16 & Corticosteroid 11-beta-dehydrogenase & DHI1_RAT & $32 \mathrm{kDa}$ & 0.65 \\
& isozyme 1 & & & \\
17 & Collectin-12 & COL12_RAT & $82 \mathrm{kDa}$ & 0.60 \\
18 & Cluster of Neurotrimin & NTRI_RAT [2] & $38 \mathrm{kDa}$ & 0.65 \\
19 & Programmed cell death protein 4 & PDCD4_RAT & $52 \mathrm{kDa}$ & 0.55 \\
20 & Plasminogen receptor (KT) & PLRKT_RAT & $17 \mathrm{kDa}$ & 0.60 \\
\hline & & & & \\
& & & & \\
& & &
\end{tabular}




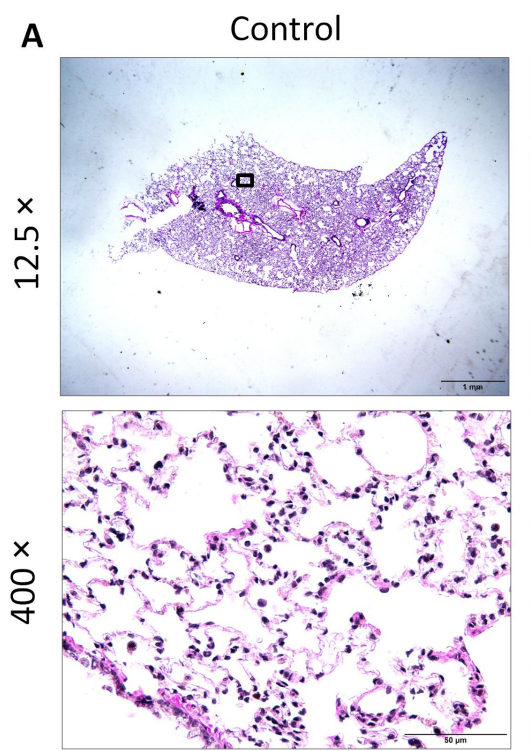

B
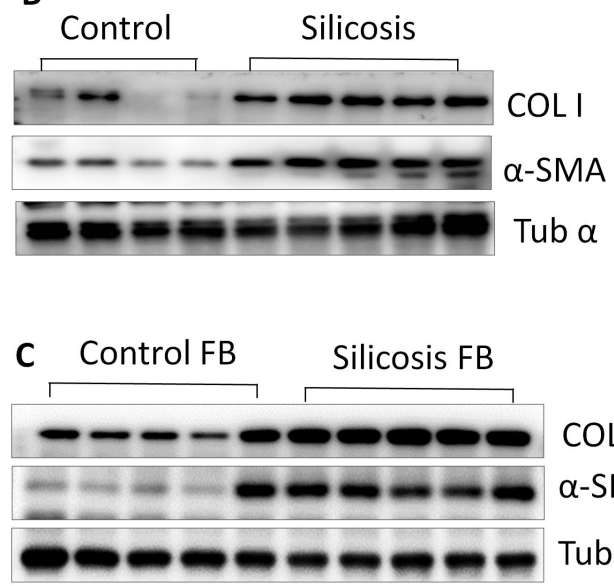

Figure 1
Silicosis

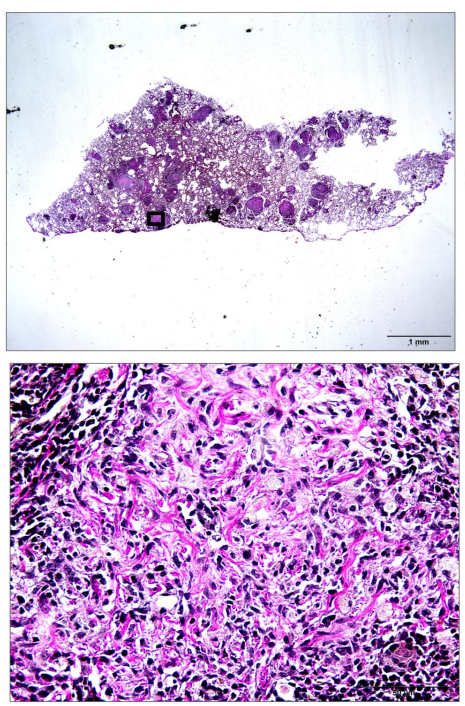

COL I

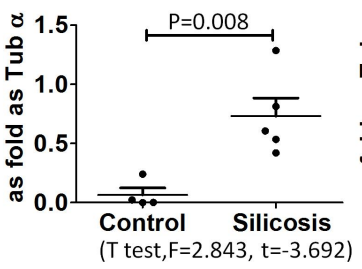

COL I

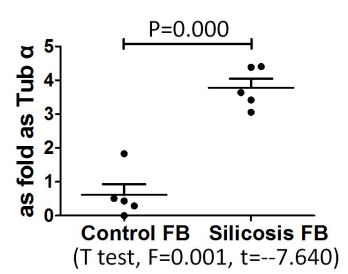

Silicotic area

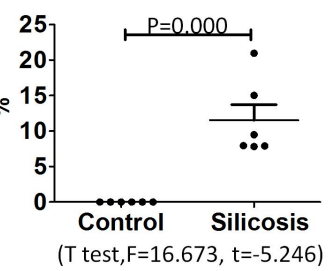

Silicotic number

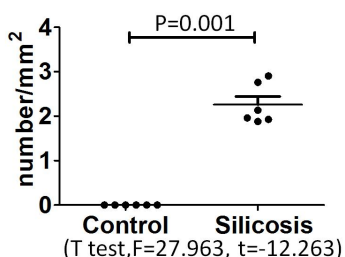

COL I

$\alpha-S M A$

Tub $\alpha$

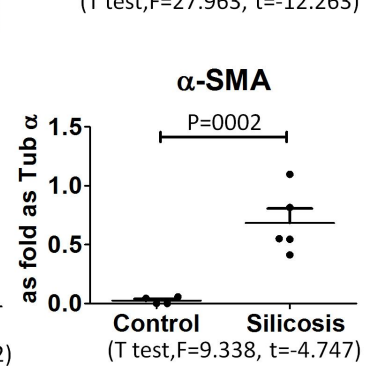

$\alpha-S M A$

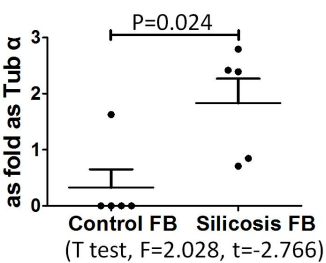

$(\mathrm{T}$ test, $\mathrm{F}=2.028, \mathrm{t}=-2.766)$

Figure 1.Histological examination of control and silica-exposed rat lung.A. Low

(top) and high (bottom) power images of control and silica-exposed lung after van Gieson (VG) staining. Right) Quantitative assessment of area and number silicotic nodules in the lungs of control and silica-exposed rats. Western blot analysis for collagen I (COLI) and $\alpha$-smooth muscle actin ( $\alpha$-SMA) in whole lung tissues and isolated fibroblasts from control and silica-exposed ratsAbbreviations: C, control; S, silicosis. Statistical significance was assessed using the Student's t-test. 

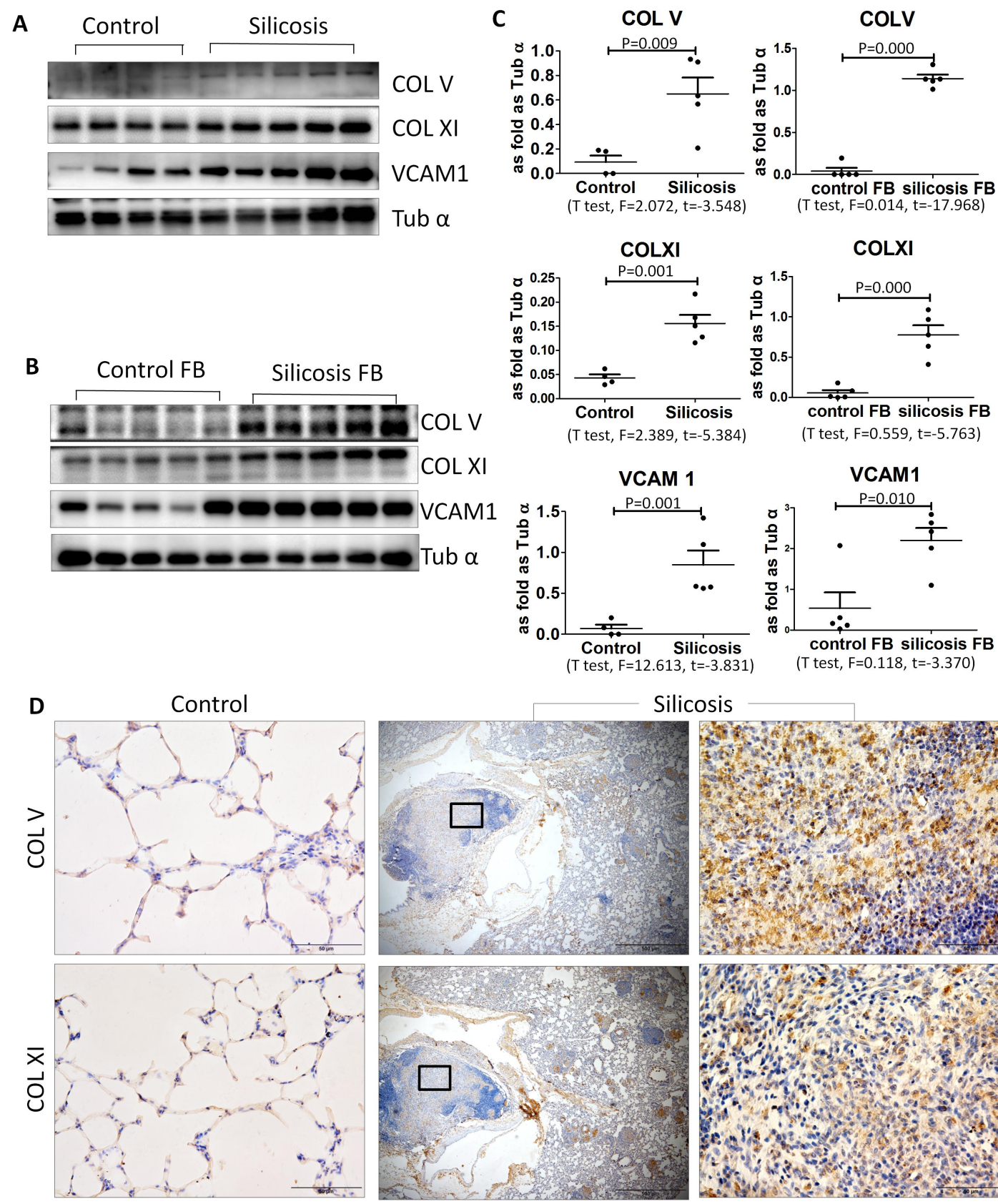

Silicosis

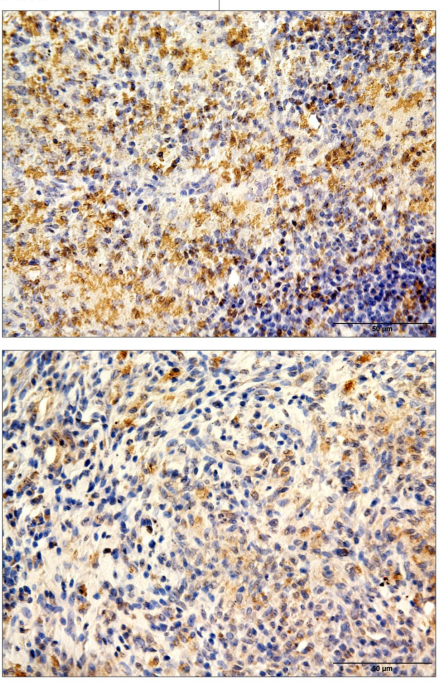

Figure 2

Figure 2. COL V, COLXI and VCAM1levels are increased in the rat lung after silicaexposure. A-C) Western blot analysis for COL V, COLXI and VCAM1 in control and silica exposed rat lung tissues. Quantitative analyses of immunoblots are shown in (C). D) IHC for expression COL V and COLXI in lung tissues from control (left) andsilica-exposed rats. Statistical significance was assessed using the Student's t-test. 

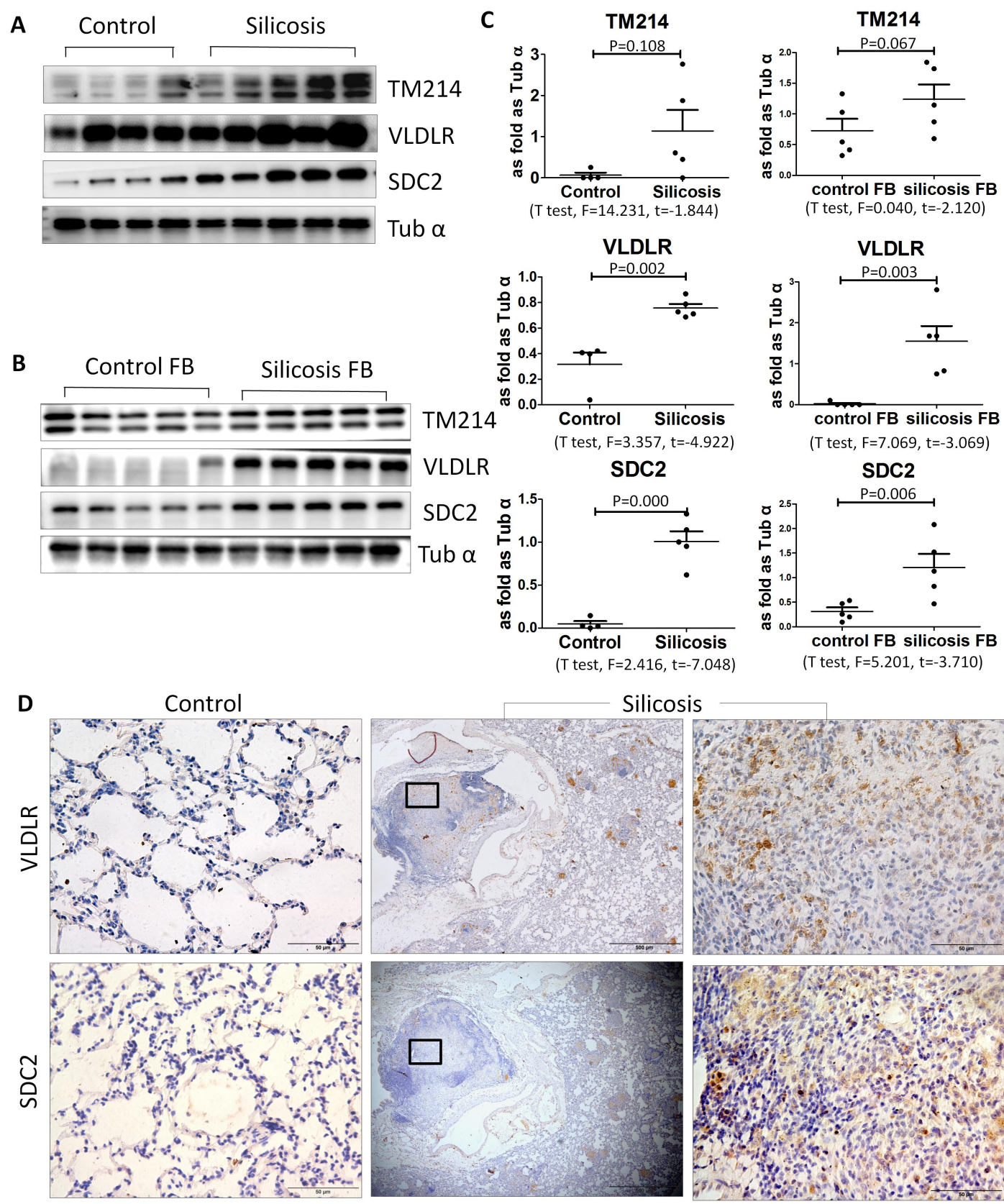

Silicosis

\section{Figure 3}

Figure 3.TM214, VLDLR and SDC2 expression is increased in the rat lung after

silica exposure. A-C) Western blot analysis for TM214, VLDLR and SDC2 in control and silica exposed rat lung tissues. Quantitative analyses of immunoblots are shown in (C).D) IHC for expression VLDLR and SDC2 in lung tissues from control (left) andsilica-exposed rats. Statistical significance was assessed using the Student's t-test. 
A

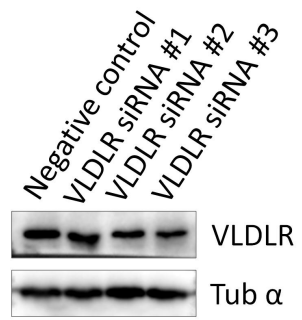

B

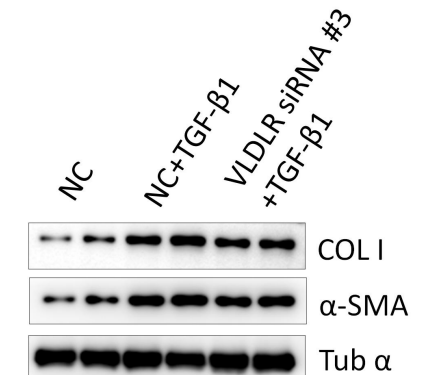

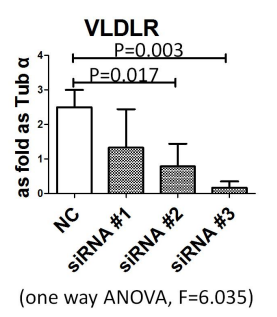

COLI

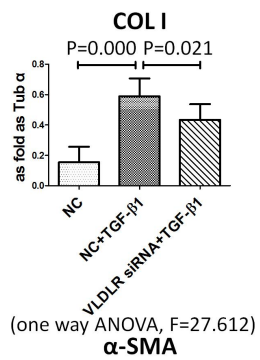

$P=0.000 P=0.000$

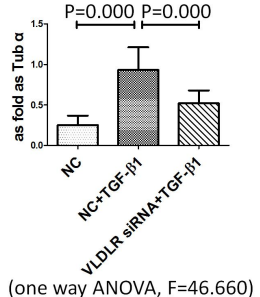

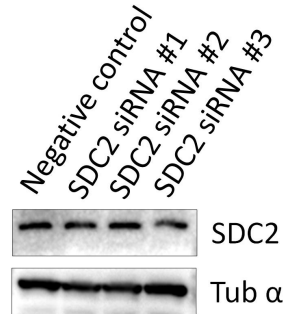
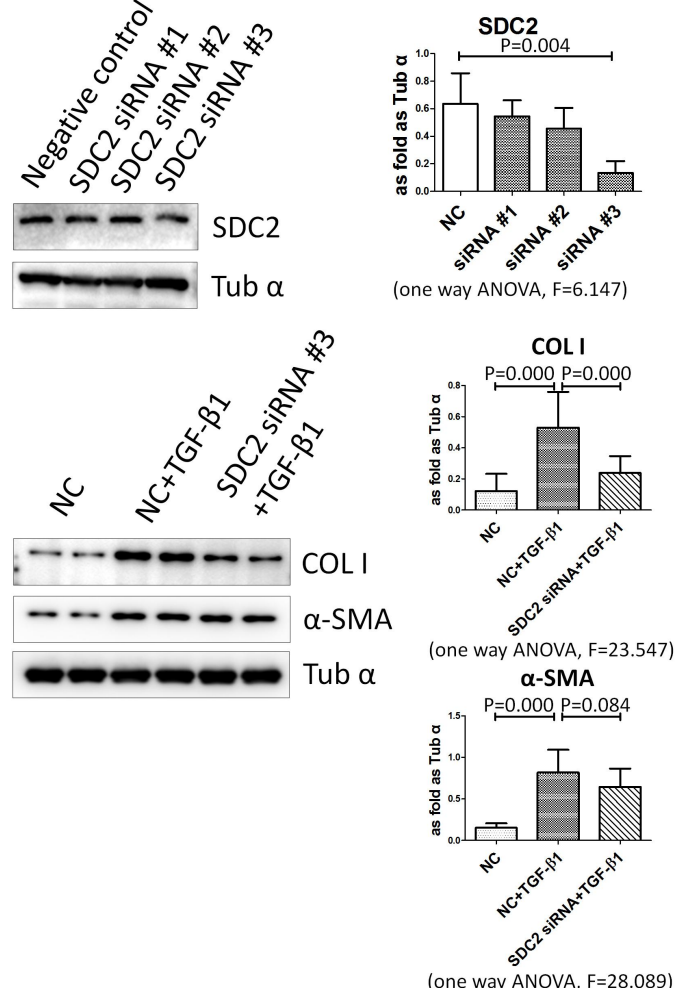

Figure 4

Figure 4. siRNA knockdown or VLDLR or SDC2 in lung fibroblasts reduces TGF-ß1-induced collagen. A) Effectiveness of different siRNA probes in knockdown expression of VLDLR or SDC2. B) siRNA knockdown of VLDLR reduces expression of COL I and $\alpha$-SMA in TGF- $\beta 1$ treated MRC-5 fibroblasts. siRNA knockdown of SDC2 reduces expression of COL1 and causes a non-significant reduction in $\alpha$-SMA in TGF- $\beta 1$ treated MRC-5 fibroblasts. Statistical significance was assessed using the one way ANOVA. 
Table S1 The down-regulation of differential proteins in fibroblasts induced by TGF- $\beta 1$

\begin{tabular}{|c|c|c|c|c|}
\hline No. & Protein Name & $\begin{array}{l}\text { Accession } \\
\text { Number }\end{array}$ & $\begin{array}{l}\text { Molecular } \\
\text { weight (Kda) }\end{array}$ & Fold \\
\hline 1 & $\begin{array}{l}\text { Histone } \mathrm{H} 4 \quad \mathrm{OS}=\text { Rattus } \\
\text { GN=Hist1h4b } \mathrm{PE}=1 \mathrm{SV}=2\end{array}$ & H4_RAT & $11 \mathrm{kDa}$ & 0.25 \\
\hline 2 & $\begin{array}{l}\text { Programmed cell death protein } 4 \mathrm{OS}=\text { Rattus } \\
\text { norvegicus } \mathrm{GN}=\mathrm{Pdcd} 4 \mathrm{PE}=1 \mathrm{SV}=2\end{array}$ & PDCD4_RAT & $52 \mathrm{kDa}$ & 0.55 \\
\hline 3 & $\begin{array}{l}\text { Serum albumin } \mathrm{OS}=\text { Rattus norvegicus } \\
\mathrm{GN}=\mathrm{Alb} \mathrm{PE}=1 \mathrm{SV}=2\end{array}$ & ALBU_RAT & $69 \mathrm{kDa}$ & 0.59 \\
\hline 4 & $\begin{array}{ll}\text { Collectin }-12 \quad \text { OS }=\text { Rattus } & \text { norvegicus } \\
\mathrm{GN}=\text { Colec } 12 \mathrm{PE}=2 \mathrm{SV}=1 & \end{array}$ & COL12_RAT & $82 \mathrm{kDa}$ & 0.60 \\
\hline 5 & $\begin{array}{l}\text { Plasminogen receptor }(\mathrm{KT}) \quad \mathrm{OS}=\text { Rattus } \\
\text { norvegicus } \mathrm{GN}=\text { Plgrkt } \mathrm{PE}=1 \mathrm{SV}=1\end{array}$ & PLRKT_RAT & $17 \mathrm{kDa}$ & 0.60 \\
\hline 6 & 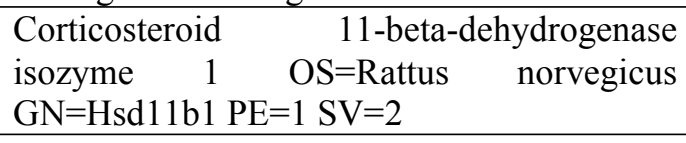 & DHI1_RAT & $32 \mathrm{kDa}$ & 0.65 \\
\hline 7 & $\begin{array}{l}\begin{array}{l}\text { Cluster of } \\
\text { norvegicus } \\
\text { (NTRI_RAT) }\end{array} \\
\text { GN=Ntm }\end{array} \quad$ PE=1 $\quad \begin{array}{r}\text { SV }=1 \\
\end{array}$ & NTRI_RAT [2] & $38 \mathrm{kDa}$ & 0.65 \\
\hline 8 & $\begin{array}{l}\text { Apolipoprotein } \mathrm{E} \quad \mathrm{OS}=\text { Rattus norvegicus } \\
\mathrm{GN}=\text { Apoe } \mathrm{PE}=1 \mathrm{SV}=2\end{array}$ & APOE_RAT & $36 \mathrm{kDa}$ & 0.70 \\
\hline 9 & $\begin{array}{l}\text { Galectin-3-binding protein } \quad \mathrm{OS}=\text { Rattus } \\
\text { norvegicus } \mathrm{GN}=\text { Lgals3bp } \mathrm{PE}=1 \mathrm{SV}=2\end{array}$ & LG3BP_RAT & $64 \mathrm{kDa}$ & 0.70 \\
\hline 10 & $\begin{array}{l}\text { Mitochondrial 2-oxoglutarate/malate carrier } \\
\text { protein } \mathrm{OS}=\text { Rattus norvegicus } \mathrm{GN}=\mathrm{Slc} 25 \mathrm{a} 11 \\
\mathrm{PE}=2 \mathrm{SV}=3\end{array}$ & M2OM_RAT & $34 \mathrm{kDa}$ & 0.70 \\
\hline 11 & $\begin{array}{l}\text { ER membrane protein complex subunit } 10 \\
\text { OS=Rattus norvegicus } \mathrm{GN}=\text { Emc } 10 \quad \mathrm{PE}=1 \\
\mathrm{SV}=1\end{array}$ & EMC10_RAT & $27 \mathrm{kDa}$ & 0.70 \\
\hline 12 & $\begin{array}{l}\text { Gap junction alpha-1 protein } \mathrm{OS}=\text { Rattus } \\
\text { norvegicus } \mathrm{GN}=\mathrm{G} \text { jal } \mathrm{PE}=1 \mathrm{SV}=2\end{array}$ & CXA1_RAT & $43 \mathrm{kDa}$ & 0.70 \\
\hline 13 & $\begin{array}{l}\text { Dystrobrevin beta } \mathrm{OS}=\text { Rattus norvegicus } \\
\mathrm{GN}=\mathrm{D} \text { tnb } \mathrm{PE}=2 \mathrm{SV}=2\end{array}$ & DTNB_RAT & $74 \mathrm{kDa}$ & 0.70 \\
\hline 14 & $\begin{array}{ll}\text { Maspardin } \quad \mathrm{OS}=\text { Rattus } & \text { norvegicus } \\
\mathrm{GN}=\mathrm{Spg} 21 \mathrm{PE}=2 \mathrm{SV}=1 & \end{array}$ & SPG21_RAT & $30 \mathrm{kDa}$ & 0.70 \\
\hline 15 & $\begin{array}{l}\text { Structural maintenance of chromosomes } \\
\text { protein } 1 \mathrm{~A} \quad \mathrm{OS}=\text { Rattus } \\
\text { GN=Smc1a } \mathrm{PE}=1 \mathrm{SV}=1\end{array}$ & SMC1A_RAT & $143 \mathrm{kDa}$ & 0.75 \\
\hline 16 & $\begin{array}{l}\text { Phosphate } \text { carrier protein, mitochondrial } \\
\text { OS=Rattus norvegicus } \mathrm{GN}=\mathrm{Slc} 25 \mathrm{a} 3 \mathrm{PE}=1 \\
\mathrm{SV}=1\end{array}$ & MPCP_RAT & $39 \mathrm{kDa}$ & 0.75 \\
\hline 17 & $\begin{array}{l}\text { Sorting and assembly machinery component } \\
50 \text { homolog OS=Rattus norvegicus } \\
\mathrm{GN}=\text { Samm50 PE }=1 \mathrm{SV}=1\end{array}$ & SAM50_RAT & $52 \mathrm{kDa}$ & 0.75 \\
\hline 18 & $\begin{array}{l}\text { ATP-binding cassette sub-family D member } \\
3 \text { OS=Rattus norvegicus } G N=A b c d 3 \quad P E=1 \\
\text { SV=3 }\end{array}$ & ABCD3_RAT & $75 \mathrm{kDa}$ & 0.75 \\
\hline 19 & $\begin{array}{l}\text { Anthrax toxin receptor } 1 \quad \mathrm{OS}=\text { Rattus } \\
\text { norvegicus } \mathrm{GN}=\text { Antxr1 } \mathrm{PE}=2 \mathrm{SV}=2\end{array}$ & ANTR1_RAT & $62 \mathrm{kDa}$ & 0.75 \\
\hline 20 & $\begin{array}{l}\text { Coiled-coil and } \mathrm{C} 2 \text { domain-containing } \\
\text { protein 1A OS=Rattus norvegicus } \\
\mathrm{GN}=\mathrm{Cc} 2 \mathrm{~d} 1 \mathrm{a} \mathrm{PE}=2 \mathrm{SV}=2\end{array}$ & C2D1A_RAT & $104 \mathrm{kDa}$ & 0.75 \\
\hline 21 & $\begin{array}{l}\text { Proteasome activator complex subunit } 2 \\
\text { OS=Rattus norvegicus } \mathrm{GN}=\mathrm{Psme} 2 \mathrm{PE}=2 \\
\mathrm{SV}=3\end{array}$ & PSME2_RAT & $27 \mathrm{kDa}$ & 0.75 \\
\hline
\end{tabular}




\begin{tabular}{|c|c|c|c|c|}
\hline 22 & $\begin{array}{l}\text { Transmembrane emp } 24 \text { domain-containing } \\
\text { protein } 2 \mathrm{OS}=\text { Rattus norvegicus } \mathrm{GN}=\mathrm{Tmed} 2 \\
\mathrm{PE}=1 \mathrm{SV}=1\end{array}$ & TMED2_RAT & $23 \mathrm{kDa}$ & 0.75 \\
\hline 23 & $\begin{array}{l}\text { Keratin, type II cytoskeletal } 4 \text { OS=Rattus } \\
\text { norvegicus } \mathrm{GN}=\mathrm{Krt} 4 \mathrm{PE}=3 \mathrm{SV}=1\end{array}$ & K2C4_RAT & $58 \mathrm{kDa}$ & 0.75 \\
\hline 24 & $\begin{array}{l}\text { ATP synthase subunit } \mathrm{d} \text {, mitochondrial } \\
\mathrm{OS}=\text { Rattus norvegicus } \mathrm{GN}=\mathrm{Atp} 5 \mathrm{~h} \quad \mathrm{PE}=1 \\
\mathrm{SV}=3\end{array}$ & ATP5H_RAT & $19 \mathrm{kDa}$ & 0.75 \\
\hline 25 & $\begin{array}{l}\text { Voltage-dependent anion-selective channel } \\
\text { protein } 3 \text { OS=Rattus norvegicus } \mathrm{GN}=\mathrm{V} \text { dac } 3 \\
\mathrm{PE}=1 \mathrm{SV}=2\end{array}$ & VDAC3_RAT & $31 \mathrm{kDa}$ & 0.75 \\
\hline 26 & $\begin{array}{l}\text { Ras GTPase-activating protein } 1 \mathrm{OS}=\text { Rattus } \\
\text { norvegicus } \mathrm{GN}=\text { Rasa1 } \mathrm{PE}=3 \mathrm{SV}=1\end{array}$ & RASA1_RAT & $115 \mathrm{kDa}$ & 0.75 \\
\hline 27 & $\begin{array}{l}\text { Gamma-adducin } \mathrm{OS}=\text { Rattus norvegicus } \\
\text { GN=Add3 } \mathrm{PE}=1 \mathrm{SV}=2\end{array}$ & ADDG_RAT & $79 \mathrm{kDa}$ & 0.75 \\
\hline 28 & $\begin{array}{l}\text { Slit homolog } 2 \text { protein } \\
\text { OS=Rattus norvegicus } \quad \text { (FNagment) } \\
\mathrm{SV}=3\end{array}$ & SLIT2_RAT & $86 \mathrm{kDa}$ & 0.75 \\
\hline 29 & $\begin{array}{lll}\text { Sequestosome-1 } & \text { OS=Rattus } & \text { norvegicus } \\
\text { GN=Sqstm } 1 \mathrm{PE}=1 \mathrm{SV}=1 & \\
\end{array}$ & SQSTM_RAT & $48 \mathrm{kDa}$ & 0.75 \\
\hline 30 & $\begin{array}{l}\text { Cluster of Hydroxymethylglutaryl-CoA } \\
\text { lyase, mitochondrial OS=Rattus norvegicus } \\
\text { GN=Hmgcl PE=2 SV=1 (HMGCL RAT) }\end{array}$ & HMGCL_RAT & $34 \mathrm{kDa}$ & 0.75 \\
\hline 31 & $\begin{array}{l}\text { Lipid phosphate phosphohydrolase } 3 \\
\text { OS=Rattus norvegicus GN=Ppap2b } \mathrm{PE}=1 \\
\mathrm{SV}=1\end{array}$ & LPP3_RAT & $35 \mathrm{kDa}$ & 0.75 \\
\hline 32 & $\begin{array}{l}\text { 39S ribosomal protein } \mathrm{L} 37 \text {, mitochondrial } \\
\mathrm{OS}=\text { Rattus norvegicus } \mathrm{GN}=\mathrm{Mrp137} \mathrm{PE}=2 \\
\mathrm{SV}=1\end{array}$ & RM37_RAT & $48 \mathrm{kDa}$ & 0.75 \\
\hline 33 & $\begin{array}{l}\text { Lipid phosphate phosphohydrolase } 1 \\
\text { OS=Rattus norvegicus GN=Ppap2a } \mathrm{PE}=1 \\
\mathrm{SV}=1\end{array}$ & LPP1_RAT & $32 \mathrm{kDa}$ & 0.75 \\
\hline 34 & $\begin{array}{l}\text { Ras-related protein Rab-13 OS=Rattus } \\
\text { norvegicus } \mathrm{GN}=\mathrm{Rab} 13 \mathrm{PE}=1 \mathrm{SV}=2\end{array}$ & RAB13_RAT & $23 \mathrm{kDa}$ & 0.75 \\
\hline 35 & $\begin{array}{l}\text { Phospholipid scramblase } 3 \quad \mathrm{OS}=\text { Rattus } \\
\text { norvegicus } \mathrm{GN}=\mathrm{Plscr} 3 \mathrm{PE}=2 \mathrm{SV}=1\end{array}$ & PLS3_RAT & $32 \mathrm{kDa}$ & 0.77 \\
\hline 36 & $\begin{array}{l}\text { Spectrin beta chain, non-erythrocytic } 2 \\
\text { OS=Rattus norvegicus GN=Sptbn2 PE=1 } \\
\mathrm{SV}=2\end{array}$ & SPTN2_RAT & $271 \mathrm{kDa}$ & 0.80 \\
\hline 37 & $\begin{array}{l}\text { Hexokinase-1 } \quad \text { OS=Rattus norvegicus } \\
\text { GN=Hk1 PE=1 SV=4 }\end{array}$ & HXK1_RAT & $102 \mathrm{kDa}$ & 0.80 \\
\hline 38 & $\begin{array}{l}\text { Unconventional myosin-Ib OS=Rattus } \\
\text { norvegicus } \mathrm{GN}=\mathrm{Myo} 1 \mathrm{~b} \mathrm{PE}=1 \mathrm{SV}=1\end{array}$ & MYO1B_RAT & $132 \mathrm{kDa}$ & 0.80 \\
\hline 39 & $\begin{array}{l}\text { Dolichyl-diphosphooligosaccharide--protein } \\
\text { glycosyltransferase subunit } 2 \text { OS=Rattus } \\
\text { norvegicus } \mathrm{GN}=\mathrm{Rpn} 2 \mathrm{PE}=2 \mathrm{SV}=2\end{array}$ & RPN2_RAT & $69 \mathrm{kDa}$ & 0.80 \\
\hline 40 & $\begin{array}{l}\text { Matrix Gla protein } \mathrm{OS}=\text { Rattus norvegicus } \\
\mathrm{GN}=\mathrm{Mgp} \mathrm{PE}=1 \mathrm{SV}=2\end{array}$ & MGP_RAT & $12 \mathrm{kDa}$ & 0.80 \\
\hline 41 & $\begin{array}{l}\text { Catalase OS=Rattus norvegicus } \mathrm{GN}=\mathrm{Cat} \\
\mathrm{PE}=1 \mathrm{SV}=3\end{array}$ & CATA_RAT & $60 \mathrm{kDa}$ & 0.80 \\
\hline 42 & $\begin{array}{l}\text { Cluster of Caveolin-1 OS=Rattus norvegicus } \\
\text { GN=Cav1 PE }=1 \mathrm{SV}=3 \text { (CAV1_RAT) }\end{array}$ & CAV1_RAT & $21 \mathrm{kDa}$ & 0.80 \\
\hline 43 & $\begin{array}{l}\text { Myeloid-associated differentiation marker } \\
\text { OS=Rattus norvegicus GN=Myadm } \mathrm{PE}=2 \\
\mathrm{SV}=1\end{array}$ & MYADM_RAT & $35 \mathrm{kDa}$ & 0.80 \\
\hline 44 & 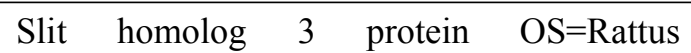 & SLIT3_RAT & $168 \mathrm{kDa}$ & 0.80 \\
\hline
\end{tabular}




\begin{tabular}{|c|c|c|c|c|}
\hline & norvegicus $\mathrm{GN}=\mathrm{S}$ lit3 $\mathrm{PE}=2 \mathrm{SV}=1$ & & & \\
\hline 45 & $\begin{array}{l}\text { Voltage-dependent anion-selective channel } \\
\text { protein } 2 \mathrm{OS}=\text { Rattus norvegicus } \mathrm{GN}=\mathrm{V} \text { dac } 2 \\
\mathrm{PE}=1 \mathrm{SV}=2\end{array}$ & VDAC2_RAT & $32 \mathrm{kDa}$ & 0.80 \\
\hline 46 & $\begin{array}{l}\text { Aldehyde dehydrogenase, } \\
\text { NADP-preferring OS=Rattus } \\
\text { GN=Aldh3a1 PE=1 SV=3 }\end{array}$ & AL3A1_RAT & $50 \mathrm{kDa}$ & 0.80 \\
\hline 47 & $\begin{array}{l}\text { Kinesin-like protein KIF1B OS=Rattus } \\
\text { norvegicus GN=Kiflb } \mathrm{PE}=1 \mathrm{SV}=2\end{array}$ & KIF1B_RAT & $204 \mathrm{kDa}$ & 0.80 \\
\hline 48 & $\begin{array}{l}\text { AP2-associated protein kinase } 1 \mathrm{OS}=\text { Rattus } \\
\text { norvegicus } \mathrm{GN}=\mathrm{Aak} 1 \mathrm{PE}=1 \mathrm{SV}=1\end{array}$ & AAK1_RAT & $104 \mathrm{kDa}$ & 0.80 \\
\hline 49 & $\begin{array}{l}\text { Serine/threonine-protein kinase } \mathrm{MRCK} \\
\text { alpha } \mathrm{OS}=\text { Rattus norvegicus } \mathrm{GN}=\mathrm{Cdc} 42 \mathrm{bpa} \\
\mathrm{PE}=1 \mathrm{SV}=1\end{array}$ & MRCKA_RAT & $197 \mathrm{kDa}$ & 0.80 \\
\hline 50 & $\begin{array}{lll}\text { Plexin-A3 } & \text { OS }=\text { Rattus } & \text { norvegicus } \\
\text { GN=Plxna3 } P E=3 \mathrm{SV}=1 & \end{array}$ & PLXA3_RAT & $208 \mathrm{kDa}$ & 0.80 \\
\hline 51 & $\begin{array}{l}\text { Keratin, type II cytoskeletal } 1 \text { OS=Rattus } \\
\text { norvegicus } \mathrm{GN}=\mathrm{Krt} 1 \mathrm{PE}=2 \mathrm{SV}=1\end{array}$ & K2C1_RAT & $65 \mathrm{kDa}$ & 0.80 \\
\hline 52 & $\begin{array}{lcc}\text { Calcium-binding } & \text { and } & \text { coiled-coil } \\
\text { domain-containing protein } & 1 & \mathrm{OS}=\text { Rattus } \\
\text { norvegicus } \mathrm{GN}=\text { Calcoco } 1 \mathrm{PE}=2 & \mathrm{SV}=1\end{array}$ & CACO1_RAT & $77 \mathrm{kDa}$ & 0.80 \\
\hline 53 & $\begin{array}{l}\text { Nucleolar transcription factor } 1 \mathrm{OS}=\text { Rattus } \\
\text { norvegicus } \mathrm{GN}=\mathrm{Ubtf} \mathrm{PE}=1 \mathrm{SV}=1\end{array}$ & UBF1_RAT & $89 \mathrm{kDa}$ & 0.80 \\
\hline 54 & $\begin{array}{l}\text { 2',3'-cyclic-nucleotide 3'-phosphodiesterase } \\
\text { OS=Rattus norvegicus GN=Cnp PE=1 SV=2 }\end{array}$ & CN37_RAT & $47 \mathrm{kDa}$ & 0.80 \\
\hline 55 & $\begin{array}{l}72 \mathrm{kDa} \text { type IV collagenase } \mathrm{OS}=\text { Rattus } \\
\text { norvegicus } \mathrm{GN}=\mathrm{Mmp} 2 \mathrm{PE}=2 \mathrm{SV}=2\end{array}$ & MMP2_RAT & $74 \mathrm{kDa}$ & 0.80 \\
\hline 56 & $\begin{array}{lll}\text { Sideroflexin-3 } & \text { OS=Rattus } & \text { norvegicus } \\
\mathrm{GN}=\mathrm{Sfxn} 3 \mathrm{PE}=2 \mathrm{SV}=1 & \\
\end{array}$ & SFXN3_RAT & $35 \mathrm{kDa}$ & 0.80 \\
\hline 57 & $\begin{array}{l}\text { Core histone macro-H2A.1 OS=Rattus } \\
\text { norvegicus GN=H2afy } \mathrm{PE}=1 \mathrm{SV}=4\end{array}$ & H2AY_RAT & $40 \mathrm{kDa}$ & 0.80 \\
\hline 58 & $\begin{array}{l}\text { 5'-nucleotidase domain-containing protein } 2 \\
\text { OS=Rattus norvegicus GN=Nt5dc2 PE }=2 \\
\text { SV }=2\end{array}$ & NT5D2_RAT & $64 \mathrm{kDa}$ & 0.80 \\
\hline 59 & $\begin{array}{lll}\text { Contactin-2 } & \text { OS }=\text { Rattus } & \text { norvegicus } \\
\mathrm{GN}=\mathrm{Cntn} 2 \mathrm{PE}=1 \mathrm{SV}=1 & \end{array}$ & CNTN2_RAT & $113 \mathrm{kDa}$ & 0.80 \\
\hline 60 & $\begin{array}{l}\text { Casein kinase II subunit alpha } \mathrm{OS}=\text { Rattus } \\
\text { norvegicus } \mathrm{GN}=\mathrm{Csnk} 2 \mathrm{a} 1 \mathrm{PE}=1 \mathrm{SV}=2\end{array}$ & CSK21_RAT & $45 \mathrm{kDa}$ & 0.80 \\
\hline 61 & $\begin{array}{l}\text { Phospholipid hydroperoxide } \text { glutathione } \\
\text { peroxidase, nuclear OS=Rattus norvegicus } \\
\text { GN=Gpx4 PE=2 SV=3 }\end{array}$ & GPX42_RAT & $29 \mathrm{kDa}$ & 0.80 \\
\hline 62 & $\begin{array}{l}\text { Disintegrin and metalloproteinase } \\
\text { domain-containing protein } 10 \text { (Fragment) } \\
\text { OS=Rattus norvegicus } \mathrm{GN}=\mathrm{Adam} 10 \mathrm{PE}=2 \\
\mathrm{SV}=1\end{array}$ & ADA10_RAT & $60 \mathrm{kDa}$ & 0.80 \\
\hline 63 & $\begin{array}{l}\text { Alpha-adducin } \quad \text { OS=Rattus norvegicus } \\
\text { GN=Add1 } \mathrm{PE}=2 \mathrm{SV}=2\end{array}$ & ADDA_RAT & $80 \mathrm{kDa}$ & 0.80 \\
\hline 64 & $\begin{array}{l}\text { Mitochondrial carnitine/acylcarnitine carrier } \\
\text { protein } \mathrm{OS}=\text { Rattus norvegicus } \mathrm{GN}=\mathrm{Slc} 25 \mathrm{a} 20 \\
\mathrm{PE}=1 \mathrm{SV}=1\end{array}$ & MCAT_RAT & $33 \mathrm{kDa}$ & 0.80 \\
\hline 65 & $\begin{array}{l}\text { Basic leucine zipper } \quad \text { and } \quad \mathrm{W} 2 \\
\text { domain-containing protein } 2 \text { OS=Rattus } \\
\text { norvegicus } \mathrm{GN}=\mathrm{Bzw} 2 \mathrm{PE}=2 \mathrm{SV}=1\end{array}$ & BZW2_RAT & $48 \mathrm{kDa}$ & 0.80 \\
\hline 66 & $\begin{array}{l}\text { Protein Wnt-5a OS=Rattus norvegicus } \\
\text { GN=Wnt5a PE }=2 \mathrm{SV}=2\end{array}$ & WNT5A_RAT & $42 \mathrm{kDa}$ & 0.80 \\
\hline 67 & Phosphatidylinositol 3-kinase regulatory & P85A_RAT & $84 \mathrm{kDa}$ & 0.80 \\
\hline
\end{tabular}




\begin{tabular}{|c|c|c|c|c|}
\hline & $\begin{array}{l}\text { subunit alpha } \quad \mathrm{OS}=\text { Rattus norvegicus } \\
\mathrm{GN}=\text { Pik3r1 } \mathrm{PE}=1 \mathrm{SV}=1\end{array}$ & & & \\
\hline 68 & $\begin{array}{l}\text { Microtubule-associated protein } \mathrm{RP} / \mathrm{EB} \\
\text { family member } 2 \mathrm{OS}=\text { Rattus norvegicus } \\
\mathrm{GN}=\text { Mapre2 } \mathrm{PE}=2 \mathrm{SV}=1\end{array}$ & MARE2_RAT & $37 \mathrm{kDa}$ & 0.80 \\
\hline 69 & $\begin{array}{l}\text { ADP-ribosyl cyclase/cyclic ADP-ribose } \\
\text { hydrolase } 2 \text { OS=Rattus norvegicus GN=Bst1 } \\
\mathrm{PE}=2 \mathrm{SV}=1\end{array}$ & BST1_RAT & $35 \mathrm{kDa}$ & 0.80 \\
\hline 70 & $\begin{array}{l}\text { Insulin-like growth factor-binding protein } 5 \\
\text { OS=Rattus norvegicus } \quad \mathrm{GN}=\operatorname{Igfb} 5 \quad \mathrm{PE}=1 \\
\mathrm{SV}=1\end{array}$ & IBP5_RAT & $30 \mathrm{kDa}$ & 0.80 \\
\hline 71 & $\begin{array}{l}\text { Trophoblast } \begin{array}{l}\text { glycoprotein } \\
\text { norvegicus } \mathrm{ON}=\mathrm{T}=\text { Rattus } \mathrm{PE}=2 \mathrm{SV}=1\end{array} \\
\end{array}$ & TPBG_RAT & $47 \mathrm{kDa}$ & 0.80 \\
\hline 72 & $\begin{array}{l}\text { Tubulin-specific chaperone } \mathrm{E} \quad \mathrm{OS}=\text { Rattus } \\
\text { norvegicus } \mathrm{GN}=\text { Tbce } \mathrm{PE}=2 \mathrm{SV}=1\end{array}$ & TBCE_RAT & $59 \mathrm{kDa}$ & 0.80 \\
\hline 73 & \begin{tabular}{llr} 
3-mercaptopyruvate & \multicolumn{2}{c}{ sulfurtransferase } \\
OS=Rattus norvegicus & GN=Mpst $\quad \mathrm{PE}=1$ \\
$\mathrm{SV}=3$ & & \\
\end{tabular} & THTM_RAT & $33 \mathrm{kDa}$ & 0.80 \\
\hline 74 & $\begin{array}{l}\text { DnaJ homolog subfamily } B \text { member } 6 \\
\text { OS=Rattus norvegicus GN=Dnajb6 } P E=1 \\
S V=1\end{array}$ & DNJB6_RAT & $39 \mathrm{kDa}$ & 0.80 \\
\hline 75 & $\begin{array}{ll}\text { Hydroxyacylglutathione } & \text { hydrolase, } \\
\text { mitochondrial } \quad \mathrm{OS}=\text { Rattus } & \text { norvegicus } \\
\mathrm{GN}=\text { Hagh } \mathrm{PE}=1 \mathrm{SV}=2 & \\
\end{array}$ & GLO2_RAT & $34 \mathrm{kDa}$ & 0.80 \\
\hline 76 & $\begin{array}{l}\text { Cathepsin L1 OS=Rattus norvegicus } \\
\mathrm{GN}=\mathrm{Cts} \mathrm{PE}=1 \mathrm{SV}=2\end{array}$ & CATL1_RAT & $38 \mathrm{kDa}$ & 0.80 \\
\hline 77 & $\begin{array}{l}\text { Magnesium transporter protein } 1 \mathrm{OS}=\text { Rattus } \\
\text { norvegicus } \mathrm{GN}=\text { Magt } 1 \mathrm{PE}=2 \mathrm{SV}=2\end{array}$ & MAGT1_RAT & $38 \mathrm{kDa}$ & 0.80 \\
\hline 78 & $\begin{array}{l}\text { Collagen triple helix repeat-containing } \\
\text { protein } 1 \mathrm{OS}=\text { Rattus norvegicus } \mathrm{GN}=\mathrm{C} \text { thrc } 1 \\
\mathrm{PE}=1 \mathrm{SV}=1\end{array}$ & CTHR1_RAT & $26 \mathrm{kDa}$ & 0.80 \\
\hline 79 & $\begin{array}{l}\text { Methylosome protein } 50 \quad \mathrm{OS}=\text { Rattus } \\
\text { norvegicus } \mathrm{GN}=\mathrm{Wdr} 77 \mathrm{PE}=1 \mathrm{SV}=1\end{array}$ & MEP50_RAT & $37 \mathrm{kDa}$ & 0.80 \\
\hline 80 & $\begin{array}{l}\text { Transmembrane } 7 \text { superfamily member } 3 \\
\text { OS=Rattus norvegicus GN=Tm7sf3 PE=2 } \\
\mathrm{SV}=1\end{array}$ & TM7S3_RAT & $64 \mathrm{kDa}$ & 0.80 \\
\hline 81 & 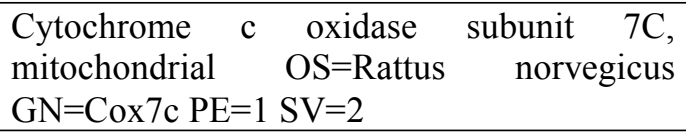 & COX7C_RAT & $7 \mathrm{kDa}$ & 0.80 \\
\hline
\end{tabular}


Table S2 The up-regulation of differential proteins in fibroblasts induced by TGF-ß1

\begin{tabular}{|c|c|c|c|c|}
\hline No. & Protein Name & $\begin{array}{l}\text { Accession } \\
\text { Number }\end{array}$ & $\begin{array}{l}\text { Molecular } \\
\text { weight (Kda) }\end{array}$ & Fold \\
\hline 1 & $\begin{array}{l}\text { Cluster of Thymosin beta-4 OS=Rattus } \\
\text { norvegicus GN=Tmsb4x PE=2 SV=2 } \\
\text { (TYB4_RAT) }\end{array}$ & TYB4_RAT & $5 \mathrm{kDa}$ & 2.50 \\
\hline 2 & $\begin{array}{l}\text { Cluster of Hemoglobin subunit beta-1 } \\
\text { OS=Rattus norvegicus } \mathrm{GN}=\mathrm{Hbb} \mathrm{PE}=1 \mathrm{SV}=3 \\
(\mathrm{HBB} 1 \text { RAT) }\end{array}$ & HBB1_RAT [2] & $16 \mathrm{kDa}$ & 2.25 \\
\hline 3 & $\begin{array}{l}\text { Hemoglobin subunit alpha- } 1 / 2 \quad \mathrm{OS}=\text { Rattus } \\
\text { norvegicus } \mathrm{GN}=\mathrm{Hba} 1 \mathrm{PE}=1 \mathrm{SV}=3\end{array}$ & HBA_RAT & $15 \mathrm{kDa}$ & 1.90 \\
\hline 4 & $\begin{array}{l}\text { Syndecan }-2 \text { OS=Rattus norvegicus } \mathrm{GN}=\mathrm{Sdc} 2 \\
\mathrm{PE}=2 \mathrm{SV}=2\end{array}$ & SDC2_RAT & $22 \mathrm{kDa}$ & 1.90 \\
\hline 5 & $\begin{array}{l}\text { Cluster of Histone H2A type } 1 \text { OS=Rattus } \\
\text { norvegicus } P E=1 \mathrm{SV}=2\left(\mathrm{H} 2 \mathrm{~A} 1 \_ \text {RAT }\right)\end{array}$ & H2A1_RAT [4] & $14 \mathrm{kDa}$ & 1.70 \\
\hline 6 & $\begin{array}{l}\text { Collagen alpha-1(XI) chain } \mathrm{OS}=\text { Rattus } \\
\text { norvegicus } \mathrm{GN}=\mathrm{Col1} 1 \mathrm{al} \mathrm{PE}=1 \mathrm{SV}=2\end{array}$ & COBA1_RAT & $181 \mathrm{kDa}$ & 1.70 \\
\hline 7 & $\begin{array}{l}\text { Collagen alpha-1(II) chain } \mathrm{OS}=\text { Rattus } \\
\text { norvegicus } \mathrm{GN}=\mathrm{Col} 2 \mathrm{a} 1 \mathrm{PE}=1 \mathrm{SV}=2\end{array}$ & CO2A1_RAT & $135 \mathrm{kDa}$ & 1.60 \\
\hline 8 & $\begin{array}{l}\text { Protein S100-A11 OS=Rattus norvegicus } \\
\mathrm{GN}=\mathrm{S} 100 \mathrm{a} 11 \mathrm{PE}=3 \mathrm{SV}=1\end{array}$ & S10AB_RAT & $11 \mathrm{kDa}$ & 1.59 \\
\hline 9 & $\begin{array}{l}\text { Vascular cell adhesion protein } 1 \mathrm{OS}=\text { Rattus } \\
\text { norvegicus } \mathrm{GN}=\mathrm{V} \text { cam } 1 \mathrm{PE}=2 \mathrm{SV}=1\end{array}$ & VCAM1_RAT & $81 \mathrm{kDa}$ & 1.55 \\
\hline 10 & $\begin{array}{l}\text { Oxidized low-density lipoprotein receptor } 1 \\
\text { OS=Rattus norvegicus } \mathrm{GN}=\mathrm{O} \operatorname{lr} 1 \mathrm{PE}=2 \mathrm{SV}=1\end{array}$ & OLR1_RAT & $42 \mathrm{kDa}$ & 1.55 \\
\hline 11 & $\begin{array}{l}\text { Very low-density lipoprotein receptor } \\
\text { OS=Rattus norvegicus } \mathrm{GN}=\mathrm{Vldll} \mathrm{PE}=2 \mathrm{SV}=1\end{array}$ & VLDLR_RAT & $97 \mathrm{kDa}$ & 1.55 \\
\hline 12 & $\begin{array}{l}\text { Collagen alpha- } 1(\mathrm{~V}) \quad \text { chain } \quad \mathrm{OS}=\text { Rattus } \\
\text { norvegicus } \mathrm{GN}=\mathrm{Col} 5 \mathrm{a} 1 \mathrm{PE}=1 \mathrm{SV}=1\end{array}$ & CO5A1_RAT & $184 \mathrm{kDa}$ & 1.50 \\
\hline 13 & $\begin{array}{l}\text { Transmembrane protein } 214 \quad \mathrm{OS}=\text { Rattus } \\
\text { norvegicus } \mathrm{GN}=\mathrm{Tmem} 214 \mathrm{PE}=2 \mathrm{SV}=1\end{array}$ & TM214_RAT & $77 \mathrm{kDa}$ & 1.50 \\
\hline 14 & $\begin{array}{l}\text { Protein-lysine } \quad \text { 6-oxidase } \quad \mathrm{OS}=\text { Rattus } \\
\text { norvegicus } \mathrm{GN}=\mathrm{Lox} \mathrm{PE}=1 \mathrm{SV}=2\end{array}$ & LYOX_RAT & $47 \mathrm{kDa}$ & 1.45 \\
\hline 15 & $\begin{array}{l}\text { ATPase inhibitor, mitochondrial } \mathrm{OS}=\text { Rattus } \\
\text { norvegicus } \mathrm{GN}=\text { Atpif1 } \mathrm{PE}=3 \mathrm{SV}=2\end{array}$ & ATIF1_RAT & $12 \mathrm{kDa}$ & 1.40 \\
\hline 16 & $\begin{array}{l}\text { Collagen alpha-1(III) chain } \mathrm{OS}=\text { Rattus } \\
\text { norvegicus } \mathrm{GN}=\mathrm{Col} 3 \mathrm{a} 1 \mathrm{PE}=2 \mathrm{SV}=3\end{array}$ & CO3A1_RAT & $139 \mathrm{kDa}$ & 1.35 \\
\hline 17 & $\begin{array}{l}\text { Tropomyosin beta chain } \quad \mathrm{OS}=\text { Rattus } \\
\text { norvegicus } \mathrm{GN}=\mathrm{Tpm} 2 \mathrm{PE}=3 \mathrm{SV}=1\end{array}$ & TPM2_RAT & $33 \mathrm{kDa}$ & 1.35 \\
\hline 18 & $\begin{array}{l}60 \mathrm{~S} \text { ribosomal protein } \mathrm{L} 26 \quad \mathrm{OS}=\text { Rattus } \\
\text { norvegicus } \mathrm{GN}=\mathrm{Rp} 126 \mathrm{PE}=1 \mathrm{SV}=1\end{array}$ & RL26_RAT & $17 \mathrm{kDa}$ & 1.35 \\
\hline 19 & $\begin{array}{l}\text { Protein PRRC1 OS=Rattus norvegicus } \\
\mathrm{GN}=\text { Prrc } 1 \mathrm{PE}=2 \mathrm{SV}=1\end{array}$ & PRRC1_RAT & $46 \mathrm{kDa}$ & 1.35 \\
\hline
\end{tabular}




\begin{tabular}{|c|c|c|c|c|}
\hline 20 & $\begin{array}{l}\text { S-adenosylmethionine synthase isoform } \\
\text { type-2 OS=Rattus norvegicus GN=Mat } 2 a \\
\mathrm{PE}=1 \mathrm{SV}=1\end{array}$ & METK2_RAT & $44 \mathrm{kDa}$ & 1.35 \\
\hline 21 & $\begin{array}{l}\text { Synaptobrevin homolog YKT6 OS=Rattus } \\
\text { norvegicus } \mathrm{GN}=\mathrm{Ykt6} \mathrm{PE}=1 \mathrm{SV}=1\end{array}$ & YKT6_RAT & $22 \mathrm{kDa}$ & 1.35 \\
\hline 22 & $\begin{array}{l}60 \mathrm{~S} \text { ribosomal protein } \mathrm{L} 37 \mathrm{a} \quad \mathrm{OS}=\text { Rattus } \\
\text { norvegicus } \mathrm{GN}=\mathrm{Rp} 137 \mathrm{a} \mathrm{PE}=1 \mathrm{SV}=1\end{array}$ & RL37A_RAT & $8 \mathrm{kDa}$ & 1.35 \\
\hline 23 & $\begin{array}{l}\text { Solute carrier family } 2 \text {, facilitated glucose } \\
\text { transporter member } 1 \text { OS=Rattus norvegicus } \\
\text { GN=Slc2a } 1 \mathrm{PE}=1 \mathrm{SV}=1\end{array}$ & GTR1_RAT & $54 \mathrm{kDa}$ & 1.35 \\
\hline 24 & $\begin{array}{l}\text { Pulmonary } \\
\text { OS }=\text { Rattus } \\
\text { nV }=3\end{array}$ & SFTPA_RAT & $26 \mathrm{kDa}$ & 1.35 \\
\hline 25 & $\begin{array}{l}\text { Small ubiquitin-related modifier } 2 \mathrm{OS}=\text { Rattus } \\
\text { norvegicus GN=Sumo2 } \mathrm{PE}=1 \mathrm{SV}=1\end{array}$ & SUMO2_RAT & $11 \mathrm{kDa}$ & 1.35 \\
\hline 26 & 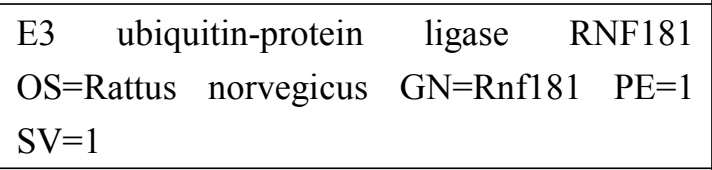 & RN181_RAT & $19 \mathrm{kDa}$ & 1.35 \\
\hline 27 & $\begin{array}{l}\text { Collagen alpha- } 1(\mathrm{I}) \quad \text { chain } \quad \mathrm{OS}=\text { Rattus } \\
\text { norvegicus } \mathrm{GN}=\mathrm{Col1} \text { a1 } \mathrm{PE}=1 \mathrm{SV}=5\end{array}$ & CO1A1_RAT & $138 \mathrm{kDa}$ & 1.30 \\
\hline 28 & $\begin{array}{l}\text { E3 ubiquitin-protein } \\
\text { OS=Rattus ligase } \quad \text { norvegicus } \\
\text { SV=1 }\end{array}$ & PZRN3_RAT & $119 \mathrm{kDa}$ & 1.30 \\
\hline 29 & $\begin{array}{l}60 \mathrm{~S} \text { ribosomal protein } \mathrm{L} 23 \mathrm{a} \quad \mathrm{OS}=\text { Rattus } \\
\text { norvegicus } \mathrm{GN}=\mathrm{Rp} 123 \mathrm{a} \mathrm{PE}=2 \mathrm{SV}=1\end{array}$ & RL23A_RAT & $18 \mathrm{kDa}$ & 1.30 \\
\hline 30 & $\begin{array}{l}40 \mathrm{~S} \text { ribosomal protein } \mathrm{S} 19 \quad \mathrm{OS}=\text { Rattus } \\
\text { norvegicus } \mathrm{GN}=\mathrm{Rps} 19 \mathrm{PE}=2 \mathrm{SV}=3\end{array}$ & RS19_RAT & $16 \mathrm{kDa}$ & 1.30 \\
\hline 31 & $\begin{array}{l}\text { Translation initiation factor eIF-2B subunit } \\
\text { gamma OS=Rattus norvegicus GN=Eif2b3 } \\
\mathrm{PE}=2 \mathrm{SV}=2\end{array}$ & EI2BG_RAT & $50 \mathrm{kDa}$ & 1.30 \\
\hline 32 & $\begin{array}{l}\text { Protein phosphatase inhibitor } 2 \mathrm{OS}=\text { Rattus } \\
\text { norvegicus } \mathrm{GN}=\mathrm{Ppp} 1 \mathrm{r} 2 \mathrm{PE}=2 \mathrm{SV}=2\end{array}$ & IPP2_RAT & $23 \mathrm{kDa}$ & 1.30 \\
\hline 33 & $\begin{array}{l}\text { PHD finger-like domain-containing protein } \\
5 \mathrm{~A} \text { OS=Rattus norvegicus } \mathrm{GN}=\mathrm{Phf5a} \mathrm{PE}=2 \\
\mathrm{SV}=1\end{array}$ & PHF5A_RAT & $12 \mathrm{kDa}$ & 1.30 \\
\hline 34 & $\begin{array}{l}\text { Ras-related protein } \mathrm{Rab}-27 \mathrm{~A} \quad \mathrm{OS}=\text { Rattus } \\
\text { norvegicus } \mathrm{GN}=\mathrm{Rab} 27 \mathrm{a} \mathrm{PE}=1 \mathrm{SV}=1\end{array}$ & RB27A_RAT & $25 \mathrm{kDa}$ & 1.30 \\
\hline 35 & $\begin{array}{l}\text { Fibroblast growth factor } 2 \text { OS=Rattus } \\
\text { norvegicus } \mathrm{GN}=\mathrm{Fgf} 2 \mathrm{PE}=2 \mathrm{SV}=1\end{array}$ & FGF2_RAT & $17 \mathrm{kDa}$ & 1.30 \\
\hline 36 & $\begin{array}{l}\begin{array}{l}\text { Proteinase-activated receptor } 1 \text { OS }=\text { Rattus } \\
\text { norvegicus } \mathrm{GN}=\mathrm{F} 2 \mathrm{r} \mathrm{PE}=2 \mathrm{SV}=1\end{array} \\
\end{array}$ & PAR1_RAT & $48 \mathrm{kDa}$ & 1.30 \\
\hline 37 & $\begin{array}{l}\text { Collagen alpha-2(I) chain } \mathrm{OS}=\text { Rattus } \\
\text { norvegicus } \mathrm{GN}=\mathrm{Col1} \mathrm{a} 2 \mathrm{PE}=1 \mathrm{SV}=3\end{array}$ & CO1A2_RAT & $130 \mathrm{kDa}$ & 1.25 \\
\hline 38 & Procollagen-lysine,2-oxoglutarate & PLOD2_RAT & $85 \mathrm{kDa}$ & 1.25 \\
\hline
\end{tabular}




\begin{tabular}{|c|c|c|c|c|}
\hline & $\begin{array}{l}\text { 5-dioxygenase } 2 \text { OS=Rattus norvegicus } \\
\mathrm{GN}=\mathrm{Plod} 2 \mathrm{PE}=2 \mathrm{SV}=1\end{array}$ & & & \\
\hline 39 & $\begin{array}{l}40 \mathrm{~S} \text { ribosomal protein } \mathrm{S} 13 \quad \mathrm{OS}=\text { Rattus } \\
\text { norvegicus } \mathrm{GN}=\mathrm{Rps} 13 \mathrm{PE}=1 \mathrm{SV}=2\end{array}$ & RS13_RAT & $17 \mathrm{kDa}$ & 1.25 \\
\hline 40 & $\begin{array}{l}\text { Plasminogen activator inhibitor } 1 \mathrm{OS}=\text { Rattus } \\
\text { norvegicus } \mathrm{GN}=\text { Serpine1 } \mathrm{PE}=2 \mathrm{SV}=1\end{array}$ & PAI1_RAT & $45 \mathrm{kDa}$ & 1.25 \\
\hline 41 & $\begin{array}{l}\text { Membrane-associated guanylate kinase, WW } \\
\text { and PDZ domain-containing protein } 3 \\
\mathrm{OS}=\text { Rattus norvegicus } \mathrm{GN}=\text { Magi3 } \mathrm{PE}=1 \\
\mathrm{SV}=2\end{array}$ & MAGI3_RAT & $161 \mathrm{kDa}$ & 1.25 \\
\hline 42 & $\begin{array}{l}\text { Plasminogen activator inhibitor } 1 \\
\text { RNA-binding protein OS=Rattus norvegicus } \\
\text { GN=Serbp1 } \mathrm{PE}=1 \mathrm{SV}=2\end{array}$ & PAIRB_RAT & $45 \mathrm{kDa}$ & 1.25 \\
\hline 43 & $\begin{array}{l}\text { Translationally-controlled tumor protein } \\
\mathrm{OS}=\text { Rattus norvegicus } \mathrm{GN}=\mathrm{Tpt} 1 \mathrm{PE}=1 \mathrm{SV}=1\end{array}$ & TCTP_RAT & $19 \mathrm{kDa}$ & 1.25 \\
\hline 44 & $\begin{array}{l}\text { Nucleolar and coiled-body phosphoprotein } 1 \\
\text { OS=Rattus norvegicus GN=Nolc1 PE=1 } \\
\mathrm{SV}=1\end{array}$ & NOLC1_RAT & $74 \mathrm{kDa}$ & 1.25 \\
\hline 45 & $\begin{array}{l}60 \mathrm{~S} \text { ribosomal protein } \mathrm{L} 35 \mathrm{a} \quad \mathrm{OS}=\text { Rattus } \\
\text { norvegicus } \mathrm{GN}=\mathrm{R} p 135 \mathrm{a} \mathrm{PE}=3 \mathrm{SV}=1\end{array}$ & RL35A_RAT & $13 \mathrm{kDa}$ & 1.25 \\
\hline 46 & $\begin{array}{l}\text { Oligoribonuclease, mitochondrial } \mathrm{OS}=\text { Rattus } \\
\text { norvegicus } \mathrm{GN}=\mathrm{Rexo} 2 \mathrm{PE}=2 \mathrm{SV}=1\end{array}$ & ORN_RAT & $27 \mathrm{kDa}$ & 1.25 \\
\hline 47 & $\begin{array}{l}\text { Protein CYR61 OS=Rattus norvegicus } \\
\text { GN=Cyr61 PE=2 SV=1 }\end{array}$ & CYR61_RAT & $42 \mathrm{kDa}$ & 1.25 \\
\hline 48 & $\begin{array}{l}\text { Protein TANC1 OS=Rattus norvegicus } \\
\text { GN=Tanc } 1 \mathrm{PE}=1 \mathrm{SV}=1\end{array}$ & TANC1_RAT & $201 \mathrm{kDa}$ & 1.25 \\
\hline 49 & $\begin{array}{l}\text { Guanine nucleotide-binding protein-like } 3 \\
\mathrm{OS}=\text { Rattus norvegicus } \mathrm{GN}=\mathrm{Gnl} 3 \mathrm{PE}=1 \mathrm{SV}=1\end{array}$ & GNL3_RAT & $61 \mathrm{kDa}$ & 1.25 \\
\hline 50 & $\begin{array}{l}\text { Glutamine--fructose-6-phosphate } \\
\text { aminotransferase [isomerizing] } 2 \text { OS=Rattus } \\
\text { norvegicus } \mathrm{GN}=\mathrm{Gfpt} 2 \mathrm{PE}=2 \mathrm{SV}=3\end{array}$ & GFPT2_RAT & $77 \mathrm{kDa}$ & 1.25 \\
\hline 51 & $\begin{array}{l}\text { Osteopontin } \mathrm{OS}=\text { Rattus norvegicus } \mathrm{GN}=\mathrm{Spp} 1 \\
\mathrm{PE}=1 \mathrm{SV}=2\end{array}$ & OSTP_RAT & $35 \mathrm{kDa}$ & 1.25 \\
\hline 52 & $\begin{array}{l}60 \mathrm{~S} \text { ribosomal protein } \mathrm{L} 36 \mathrm{a} \quad \mathrm{OS}=\text { Rattus } \\
\text { norvegicus } \mathrm{GN}=\mathrm{R} p 136 \mathrm{a} \mathrm{PE}=1 \mathrm{SV}=2\end{array}$ & RL36A_RAT & $12 \mathrm{kDa}$ & 1.25 \\
\hline 53 & $\begin{array}{l}\text { CDK5 regulatory subunit-associated protein } 3 \\
\mathrm{OS}=\text { Rattus norvegicus } \mathrm{GN}=\mathrm{Cdk} 5 \mathrm{rap} 3 \mathrm{PE}=1 \\
\mathrm{SV}=1\end{array}$ & CK5P3_RAT & $57 \mathrm{kDa}$ & 1.25 \\
\hline 54 & $\begin{array}{l}40 \mathrm{~S} \text { ribosomal protein } \mathrm{S} 25 \quad \mathrm{OS}=\text { Rattus } \\
\text { norvegicus } \mathrm{GN}=\mathrm{Rps} 25 \mathrm{PE}=2 \mathrm{SV}=1\end{array}$ & RS25_RAT & $14 \mathrm{kDa}$ & 1.25 \\
\hline 55 & $\begin{array}{l}\text { Growth factor receptor-bound protein } 10 \\
\mathrm{OS}=\text { Rattus norvegicus } \mathrm{GN}=\mathrm{Grb} 10 \quad \mathrm{PE}=3 \\
\mathrm{SV}=1\end{array}$ & GRB10_RAT & $68 \mathrm{kDa}$ & 1.25 \\
\hline 56 & ADP-ribosylation factor GTPase-activating & ARFG1_RAT & $45 \mathrm{kDa}$ & 1.25 \\
\hline
\end{tabular}




\begin{tabular}{|c|c|c|c|c|}
\hline & $\begin{array}{l}\text { protein } 1 \mathrm{OS}=\text { Rattus norvegicus } \mathrm{GN}=\text { Arfgap } 1 \\
\mathrm{PE}=1 \mathrm{SV}=1\end{array}$ & & & \\
\hline 57 & $\begin{array}{l}\text { Squalene synthase OS=Rattus norvegicus } \\
\text { GN=Fdft1 } \mathrm{PE}=2 \mathrm{SV}=1\end{array}$ & FDFT_RAT & $48 \mathrm{kDa}$ & 1.25 \\
\hline 58 & $\begin{array}{l}\text { Striatin-3 OS=Rattus norvegicus } \mathrm{GN}=\mathrm{Strn} 3 \\
\mathrm{PE}=2 \mathrm{SV}=2\end{array}$ & STRN3_RAT & $87 \mathrm{kDa}$ & 1.25 \\
\hline 59 & $\begin{array}{l}\text { Squalene monooxygenase } \quad \text { OS=Rattus } \\
\text { norvegicus } \mathrm{GN}=\text { Sqle } \mathrm{PE}=2 \mathrm{SV}=1\end{array}$ & ERG1_RAT & $64 \mathrm{kDa}$ & 1.25 \\
\hline 60 & $\begin{array}{l}\text { Calcium-regulated heat stable protein } 1 \\
\text { OS=Rattus norvegicus } \mathrm{GN}=\text { Carhsp } 1 \quad \mathrm{PE}=1 \\
\mathrm{SV}=1\end{array}$ & CHSP1_RAT & $16 \mathrm{kDa}$ & 1.25 \\
\hline 61 & $\begin{array}{l}\text { Rho guanine nucleotide exchange factor } 6 \\
\text { OS=Rattus norvegicus GN=Arhgef6 } \mathrm{PE}=2 \\
\mathrm{SV}=1\end{array}$ & ARHG6_RAT & $87 \mathrm{kDa}$ & 1.25 \\
\hline 62 & $\begin{array}{l}\text { DnaJ homolog subfamily } C \text { member } 25 \\
\text { OS=Rattus norvegicus GN=Dnajc25 PE=2 } \\
\mathrm{SV}=1\end{array}$ & DJC25_RAT & $42 \mathrm{kDa}$ & 1.25 \\
\hline 63 & $\begin{array}{l}\text { ER membrane protein complex subunit } 8 \\
\text { OS=Rattus norvegicus } \mathrm{GN}=\mathrm{Emc} 8 \quad \mathrm{PE}=2 \\
\mathrm{SV}=1\end{array}$ & EMC8_RAT & $23 \mathrm{kDa}$ & 1.25 \\
\hline 64 & $\begin{array}{l}\text { Glutamate--cysteine ligase regulatory subunit } \\
\text { OS=Rattus norvegicus } \mathrm{GN}=\mathrm{Gclm} \quad \mathrm{PE}=1 \\
\mathrm{SV}=1\end{array}$ & GSH0_RAT & $31 \mathrm{kDa}$ & 1.25 \\
\hline 65 & $\begin{array}{l}\text { Small ubiquitin-related modifier } 3 \text { OS=Rattus } \\
\text { norvegicus GN=Sumo } 3 \mathrm{PE}=3 \mathrm{SV}=1\end{array}$ & SUMO3_RAT & $12 \mathrm{kDa}$ & 1.25 \\
\hline 66 & $\begin{array}{l}\text { Leucine-rich repeat flightless-interacting } \\
\text { protein } 1 \mathrm{OS}=\text { Rattus norvegicus } \mathrm{GN}=\text { Lrrfip } 1 \\
\mathrm{PE}=1 \mathrm{SV}=1\end{array}$ & LRRF1_RAT & $80 \mathrm{kDa}$ & 1.20 \\
\hline 67 & $\begin{array}{l}40 \mathrm{~S} \text { ribosomal protein } \mathrm{S} 12 \text { OS=Rattus } \\
\text { norvegicus } \mathrm{GN}=\mathrm{Rps} 12 \mathrm{PE}=1 \mathrm{SV}=2\end{array}$ & RS12_RAT & $15 \mathrm{kDa}$ & 1.20 \\
\hline 68 & $\begin{array}{l}\text { Serine/threonine-protein phosphatase } 2 \mathrm{~A} 65 \\
\mathrm{kDa} \text { regulatory subunit } \mathrm{A} \text { beta isoform } \\
\mathrm{OS}=\text { Rattus norvegicus } \mathrm{GN}=\mathrm{Ppp} 2 \mathrm{r} 1 \mathrm{~b} \mathrm{PE}=2 \\
\mathrm{SV}=1\end{array}$ & 2AAB_RAT & $66 \mathrm{kDa}$ & 1.20 \\
\hline 69 & $\begin{array}{l}\text { Acyl-protein thioesterase } 2 \quad \mathrm{OS}=\text { Rattus } \\
\text { norvegicus GN=Lypla2 } \mathrm{PE}=1 \mathrm{SV}=1\end{array}$ & LYPA2_RAT & $25 \mathrm{kDa}$ & 1.20 \\
\hline 70 & $\begin{array}{l}\text { Phosducin-like protein } 3 \quad \mathrm{OS}=\text { Rattus } \\
\text { norvegicus } \mathrm{GN}=\mathrm{Pdcl} 3 \mathrm{PE}=2 \mathrm{SV}=1\end{array}$ & PDCL3_RAT & $28 \mathrm{kDa}$ & 1.20 \\
\hline 71 & $\begin{array}{l}\begin{array}{l}\text { Dihydrofolate } \quad \text { reductase } \\
\text { norvegicus } \mathrm{GN}=\mathrm{OShfr} \mathrm{PE}=2 \mathrm{SV}=3\end{array} \\
\end{array}$ & DYR_RAT & $22 \mathrm{kDa}$ & 1.20 \\
\hline 72 & $\begin{array}{l}\begin{array}{l}\text { Alkyldihydroxyacetonephosphate } \\
\text { peroxisomal } \quad \text { Synthase, }\end{array} \\
\text { GN=Agps } \mathrm{PE}=2 \mathrm{SV}=1\end{array}$ & ADAS_RAT & $72 \mathrm{kDa}$ & 1.20 \\
\hline 73 & Arylsulfatase $\mathrm{B} \quad \mathrm{OS}=$ Rattus norvegicus & ARSB_RAT & $59 \mathrm{kDa}$ & 1.20 \\
\hline
\end{tabular}




\begin{tabular}{|c|c|c|c|c|}
\hline & $\mathrm{GN}=\mathrm{Arsb} \mathrm{PE}=2 \mathrm{SV}=2$ & & & \\
\hline 74 & $\begin{array}{l}\text { 60S ribosomal protein } \mathrm{L} 36 \quad \mathrm{OS}=\text { Rattus } \\
\text { norvegicus } \mathrm{GN}=\mathrm{R} p 136 \mathrm{PE}=1 \mathrm{SV}=2\end{array}$ & RL36_RAT & $12 \mathrm{kDa}$ & 1.20 \\
\hline 75 & $\begin{array}{lll}\text { Malignant } & \text { T-cell-amplified } & \text { sequence } 1 \\
\text { OS=Rattus } & \text { norvegicus } \quad \mathrm{GN}=\text { Mcts } 1 \quad \mathrm{PE}=2 \\
\mathrm{SV}=1 & & \end{array}$ & MCTS1_RAT & $21 \mathrm{kDa}$ & 1.20 \\
\hline 76 & $\begin{array}{l}\text { Calcium-binding mitochondrial carrier } \\
\text { protein } \mathrm{SCaMC}-2 \quad \mathrm{OS}=\text { Rattus norvegicus } \\
\mathrm{GN}=\mathrm{Slc} 25 \mathrm{a} 25 \mathrm{PE}=1 \mathrm{SV}=1\end{array}$ & SCMC2_RAT & $53 \mathrm{kDa}$ & 1.20 \\
\hline 77 & $\begin{array}{l}\text { V-type proton ATPase subunit } \mathrm{F} \text { OS=Rattus } \\
\text { norvegicus } \mathrm{GN}=\mathrm{Atp} 6 \mathrm{v} \text { 1f } \mathrm{PE}=1 \mathrm{SV}=1\end{array}$ & VATF_RAT & $13 \mathrm{kDa}$ & 1.20 \\
\hline 78 & $\begin{array}{l}\text { PEST proteolytic signal-containing nuclear } \\
\text { protein OS=Rattus norvegicus } \mathrm{GN}=\text { Pcnp } \\
\mathrm{PE}=2 \mathrm{SV}=1\end{array}$ & PCNP_RAT & $20 \mathrm{kDa}$ & 1.20 \\
\hline 79 & $\begin{array}{l}\text { Protein disulfide-isomerase } \mathrm{OS}=\text { Rattus } \\
\text { norvegicus } \mathrm{GN}=\mathrm{P} 4 \mathrm{hb} \mathrm{PE}=1 \mathrm{SV}=2\end{array}$ & PDIA1_RAT & $57 \mathrm{kDa}$ & 1.20 \\
\hline 80 & $\begin{array}{l}78 \mathrm{kDa} \text { glucose-regulated protein } \mathrm{OS}=\text { Rattus } \\
\text { norvegicus } \mathrm{GN}=\mathrm{Hspa} 5 \mathrm{PE}=1 \mathrm{SV}=1\end{array}$ & GRP78_RAT & $72 \mathrm{kDa}$ & 1.20 \\
\hline 81 & $\begin{array}{l}40 \mathrm{~S} \text { ribosomal protein } \mathrm{S} 3 \mathrm{a} \quad \mathrm{OS}=\text { Rattus } \\
\text { norvegicus } \mathrm{GN}=\mathrm{Rps} 3 \mathrm{a} \mathrm{PE}=1 \mathrm{SV}=2\end{array}$ & RS3A_RAT & $30 \mathrm{kDa}$ & 1.20 \\
\hline 82 & $\begin{array}{l}\text { Custer of Ras-related protein Rab-1A } \\
\text { OS=Rattus norvegicus GN=Rab1A PE=1 } \\
\text { SV=3 (RAB1A_RAT) }\end{array}$ & $\begin{array}{l}\text { RAB1A_RAT } \\
\text { [2] }\end{array}$ & $23 \mathrm{kDa}$ & 1.20 \\
\hline 83 & $\begin{array}{l}\text { Farnesyl pyrophosphate synthase } \mathrm{OS}=\text { Rattus } \\
\text { norvegicus } \mathrm{GN}=\mathrm{Fdps} \mathrm{PE}=2 \mathrm{SV}=2\end{array}$ & FPPS_RAT & $41 \mathrm{kDa}$ & 1.20 \\
\hline 84 & $\begin{array}{l}40 \mathrm{~S} \text { ribosomal protein } \mathrm{S} 16 \quad \mathrm{OS}=\text { Rattus } \\
\text { norvegicus } \mathrm{GN}=\mathrm{Rps} 16 \mathrm{PE}=1 \mathrm{SV}=2\end{array}$ & RS16_RAT & $16 \mathrm{kDa}$ & 1.20 \\
\hline 85 & $\begin{array}{l}40 \mathrm{~S} \text { ribosomal protein } \mathrm{S} 18 \quad \mathrm{OS}=\text { Rattus } \\
\text { norvegicus } \mathrm{GN}=\mathrm{Rps} 18 \mathrm{PE}=1 \mathrm{SV}=3\end{array}$ & RS18_RAT & $18 \mathrm{kDa}$ & 1.20 \\
\hline 86 & $\begin{array}{l}40 \mathrm{~S} \text { ribosomal protein } \mathrm{S} 11 \quad \mathrm{OS}=\text { Rattus } \\
\text { norvegicus } \mathrm{GN}=\mathrm{Rps} 11 \mathrm{PE}=1 \mathrm{SV}=3\end{array}$ & RS11_RAT & $18 \mathrm{kDa}$ & 1.20 \\
\hline 87 & $\begin{array}{l}\begin{array}{l}\text { Transforming protein } \text { RhoA } \mathrm{OS}=\text { Rattus } \\
\text { norvegicus } \mathrm{GN}=\mathrm{Rhoa} \mathrm{PE}=1 \mathrm{SV}=1\end{array}\end{array}$ & RHOA_RAT & $22 \mathrm{kDa}$ & 1.20 \\
\hline 88 & $\begin{array}{l}\text { Tubulin-specific chaperone A OS=Rattus } \\
\text { norvegicus } G N=T \text { tbca } P E=1 \mathrm{SV}=1\end{array}$ & TBCA_RAT & $13 \mathrm{kDa}$ & 1.20 \\
\hline 89 & $\begin{array}{l}\text { Transcriptional activator protein } \text { Pur-beta } \\
\mathrm{OS}=\text { Rattus norvegicus } \mathrm{GN}=\mathrm{Purb} \mathrm{PE}=1 \mathrm{SV}=3\end{array}$ & PURB_RAT & $33 \mathrm{kDa}$ & 1.20 \\
\hline 90 & $\begin{array}{l}60 \mathrm{~S} \text { ribosomal protein } \mathrm{L} 10 \mathrm{a} \text { OS=Rattus } \\
\text { norvegicus } \mathrm{GN}=\mathrm{R} p 110 \mathrm{a} \mathrm{PE}=1 \mathrm{SV}=2\end{array}$ & RL10A_RAT & $25 \mathrm{kDa}$ & 1.20 \\
\hline 91 & $\begin{array}{l}60 \mathrm{~S} \text { ribosomal protein } \mathrm{L} 11 \text { OS=Rattus } \\
\text { norvegicus } \mathrm{GN}=\mathrm{R} p 111 \mathrm{PE}=1 \mathrm{SV}=2\end{array}$ & RL11_RAT & $20 \mathrm{kDa}$ & 1.20 \\
\hline 92 & $\begin{array}{l}40 \mathrm{~S} \text { ribosomal protein } \mathrm{S} 20 \quad \mathrm{OS}=\text { Rattus } \\
\text { norvegicus } \mathrm{GN}=\mathrm{Rps} 20 \mathrm{PE}=3 \mathrm{SV}=1\end{array}$ & RS20_RAT & $13 \mathrm{kDa}$ & 1.20 \\
\hline 93 & Procollagen C-endopeptidase enhancer 1 & PCOC1_RAT & $50 \mathrm{kDa}$ & 1.20 \\
\hline
\end{tabular}




\begin{tabular}{|c|c|c|c|c|}
\hline & $\begin{array}{l}\mathrm{OS}=\text { Rattus norvegicus } \mathrm{GN}=\mathrm{Pcolce} \quad \mathrm{PE}=1 \\
\mathrm{SV}=1\end{array}$ & & & \\
\hline 94 & $\begin{array}{l}60 \mathrm{~S} \text { ribosomal protein } \mathrm{L} 17 \text { OS=Rattus } \\
\text { norvegicus } \mathrm{GN}=\mathrm{Rp} 117 \mathrm{PE}=2 \mathrm{SV}=3\end{array}$ & RL17_RAT & $21 \mathrm{kDa}$ & 1.20 \\
\hline 95 & $\begin{array}{l}\text { Phosphatidylinositol-binding } \\
\text { assembly protein } \quad \text { clathrin } \\
\text { GN=Pattus } \\
\text { norvegicus }\end{array}$ & PICAL_RAT & $69 \mathrm{kDa}$ & 1.20 \\
\hline 96 & $\begin{array}{l}\text { Translocon-associated protein subunit alpha } \\
\mathrm{OS}=\text { Rattus norvegicus } \mathrm{GN}=\mathrm{S} s \mathrm{P} 1 \mathrm{PE}=2 \mathrm{SV}=1\end{array}$ & SSRA_RAT & $36 \mathrm{kDa}$ & 1.20 \\
\hline 97 & $\begin{array}{l}\text { Protein FAM98A OS=Rattus norvegicus } \\
\text { GN=Fam98a } P E=2 \mathrm{SV}=1\end{array}$ & FA98A_RAT & $55 \mathrm{kDa}$ & 1.20 \\
\hline 98 & $\begin{array}{l}\text { Follistatin-related protein } 1 \quad \mathrm{OS}=\text { Rattus } \\
\text { norvegicus } \mathrm{GN}=\text { Fstl1 } \mathrm{PE}=1 \mathrm{SV}=1\end{array}$ & FSTL1_RAT & $35 \mathrm{kDa}$ & 1.20 \\
\hline 99 & $\begin{array}{l}\text { Cytosolic phospholipase } \mathrm{A} 2 \quad \mathrm{OS}=\text { Rattus } \\
\text { norvegicus } \mathrm{GN}=\mathrm{Pla} 2 \mathrm{~g} 4 \mathrm{a} \mathrm{PE}=2 \mathrm{SV}=1\end{array}$ & PA24A_RAT & $86 \mathrm{kDa}$ & 1.20 \\
\hline 100 & $\begin{array}{lll}\text { Protein phosphatase } & \text { methylesterase } 1 \\
\text { OS=Rattus norvegicus } & \text { GN=Ppme1 } \mathrm{PE}=1 \\
\mathrm{SV}=2 & & \end{array}$ & PPME1_RAT & $42 \mathrm{kDa}$ & 1.20 \\
\hline 101 & $\begin{array}{l}\text { Cysteine-rich protein } 2 \mathrm{OS}=\text { Rattus norvegicus } \\
\mathrm{GN}=\text { Crip2 } \mathrm{PE}=2 \mathrm{SV}=1\end{array}$ & CRIP2_RAT & $23 \mathrm{kDa}$ & 1.20 \\
\hline 102 & $\begin{array}{l}40 \mathrm{~S} \text { ribosomal protein } \mathrm{S} 17 \quad \mathrm{OS}=\text { Rattus } \\
\text { norvegicus } \mathrm{GN}=\mathrm{Rps} 17 \mathrm{PE}=1 \mathrm{SV}=3\end{array}$ & RS17_RAT & $16 \mathrm{kDa}$ & 1.20 \\
\hline 103 & $\begin{array}{l}\text { Phosphoserine phosphatase } \mathrm{OS}=\text { Rattus } \\
\text { norvegicus } \mathrm{GN}=\mathrm{Psph} \mathrm{PE}=2 \mathrm{SV}=1\end{array}$ & SERB_RAT & $25 \mathrm{kDa}$ & 1.20 \\
\hline 104 & $\begin{array}{l}\begin{array}{l}\text { Cystathionine gamma-lyase } \\
\text { norvegicus } \mathrm{GN}=\mathrm{C}=\mathrm{C} \text { th } \mathrm{PE}=1 \mathrm{SV}=2\end{array} \\
\end{array}$ & CGL_RAT & $44 \mathrm{kDa}$ & 1.20 \\
\hline 105 & $\begin{array}{l}\text { Glia maturation factor beta } \mathrm{OS}=\text { Rattus } \\
\text { norvegicus } \mathrm{GN}=\mathrm{Gmfb} \mathrm{PE}=1 \mathrm{SV}=2\end{array}$ & GMFB_RAT & $17 \mathrm{kDa}$ & 1.20 \\
\hline 106 & $\begin{array}{l}\text { Prothrombin } \mathrm{OS}=\text { Rattus norvegicus } \mathrm{GN}=\mathrm{F} 2 \\
\mathrm{PE}=1 \mathrm{SV}=1\end{array}$ & THRB_RAT & $70 \mathrm{kDa}$ & 1.20 \\
\hline 107 & $\begin{array}{l}\text { Calcyclin-binding protein } \quad \mathrm{OS}=\text { Rattus } \\
\text { norvegicus } \mathrm{GN}=\text { Cacybp } \mathrm{PE}=1 \mathrm{SV}=1\end{array}$ & CYBP_RAT & $27 \mathrm{kDa}$ & 1.20 \\
\hline 108 & $\begin{array}{ll}\text { 3-hydroxyisobutyryl-CoA } & \text { hydrolase, } \\
\text { mitochondrial } \quad \text { OS=Rattus } & \text { norvegicus } \\
\text { GN=Hibch } \mathrm{PE}=1 \mathrm{SV}=2 & \end{array}$ & HIBCH_RAT & $43 \mathrm{kDa}$ & 1.20 \\
\hline 109 & $\begin{array}{l}40 \mathrm{~S} \text { ribosomal protein } \mathrm{S} 24 \quad \mathrm{OS}=\mathrm{Rattus} \\
\text { norvegicus } \mathrm{GN}=\mathrm{Rps} 24 \mathrm{PE}=2 \mathrm{SV}=1\end{array}$ & RS24_RAT & $15 \mathrm{kDa}$ & 1.20 \\
\hline 110 & $\begin{array}{l}\text { Pyridoxal kinase } \mathrm{OS}=\text { Rattus norvegicus } \\
\mathrm{GN}=\mathrm{Pdxk} \mathrm{PE}=1 \mathrm{SV}=1\end{array}$ & PDXK_RAT & $35 \mathrm{kDa}$ & 1.20 \\
\hline 111 & $\begin{array}{l}\text { Sodium/potassium-transporting } \\
\text { subunit beta-1 OS=Rattus } \\
\text { GN=Atp1b1 } \mathrm{PE}=1 \mathrm{SV}=1\end{array}$ & AT1B1_RAT & $35 \mathrm{kDa}$ & 1.20 \\
\hline 112 & $\begin{array}{l}\text { ER membrane protein complex subunit } 3 \\
\text { OS=Rattus norvegicus } \mathrm{GN}=\mathrm{Emc} 3 \quad \mathrm{PE}=2\end{array}$ & EMC3_RAT & $30 \mathrm{kDa}$ & 1.20 \\
\hline
\end{tabular}




\begin{tabular}{|c|l|l|l|l|} 
& $\mathrm{SV}=3$ & & \\
\hline 113 & $\begin{array}{l}40 \mathrm{~S} \text { ribosomal protein S28 OS=Rattus } \\
\text { norvegicus GN=Rps28 PE=1 SV=1 }\end{array}$ & RS28_RAT & $8 \mathrm{kDa}$ & 1.20 \\
\hline 114 & $\begin{array}{l}\text { Cell growth regulator with EF hand domain } \\
\text { protein 1 OS=Rattus norvegicus GN=Cgref1 } \\
\text { PE=1 SV=1 }\end{array}$ & CGRE1_RAT & $31 \mathrm{kDa}$ & 1.20 \\
\hline 115 & $\begin{array}{l}40 \mathrm{~S} \text { ribosomal protein S27 OS=Rattus } \\
\text { norvegicus GN=Rps27 PE=2 SV=3 }\end{array}$ & RS27_RAT & $9 \mathrm{kDa}$ & 1.20 \\
\hline
\end{tabular}


Table S3. GO analysis of differential proteins performed in PANTHER and classified based on molecular function

\begin{tabular}{|c|c|c|c|c|}
\hline $\begin{array}{l}\text { molecular } \\
\text { function }\end{array}$ & & Up-regulated proteins & & Down-regulated proteins \\
\hline $\begin{array}{l}\text { catalytic activity } \\
(\mathrm{GO}: 0003824)\end{array}$ & 37 & $\begin{array}{l}\text { PDCL3; LYOX; TANC1; GMFB; CGL; FPPS; VATF; PDIA1; } \\
\text { PCOC1; PPME1; ARHG6; LYPA2; SERB; TPM2; PDXK; } \\
\text { ARSB; ERG1; ORN; EI2BG; RHOA; HIBCH; CK5P3; 2AAB; } \\
\text { METK2; GFPT2; DYR; THRB; MAGI3; PAI1; PA24A; CYBP; } \\
\text { ARFG1; ADAS; ATIF1; IPP2; GSH0; GNL3 }\end{array}$ & 28 & $\begin{array}{l}\text { KIF1B; SMC1A; THTM; MRCKA; CAV1; BST1; CATL1; } \\
\text { AL3A1; CATA; RPN2; CN37; CTHR1; LPP3; DHI1; PSME2; } \\
\text { RASA1; COX7C; LPP1; P85A; GLO2; MAGT1; AAK1; } \\
\text { BZW2; APOE; MYO1B; HXK1; NT5D2; HMGCL }\end{array}$ \\
\hline $\begin{array}{c}\text { binding } \\
(\mathrm{GO}: 0005488)\end{array}$ & 24 & $\begin{array}{c}\text { GMFB; FGF2; CRIP2; SSRA; PCOC1; PAIRB; ARHG6; } \\
\text { RL10A; S10AB; SERB; PURB; EI2BG; LRRF1; RHOA; } \\
\text { FSTL1; CYR61; OLR1; TCTP; ARFG1; CHSP1; RS13; ATIF1; } \\
\text { RL35A; YKT6 }\end{array}$ & 18 & $\begin{array}{c}\text { SMC1A; CAV1; CATA; ADDG; MARE2; DTNB; H2AY; } \\
\text { SQSTM; P85A; SPTN2; IBP5; AAK1; ADDA; C2D1A; APOE; } \\
\text { H4; MYO1B; WNT5A }\end{array}$ \\
\hline $\begin{array}{l}\text { structural } \\
\text { molecule activity } \\
(\mathrm{GO}: 0005198)\end{array}$ & 19 & $\begin{array}{c}\text { RL11; RS11; CRIP2; RS20; RS12; RS28; RS16; RL10A; RS27; } \\
\text { SCMC2; TPM2; RS18; RL23A; RL36; RL26; RS19; TCTP; } \\
\text { RS13; RL35A }\end{array}$ & 14 & $\begin{array}{l}\text { CAV1; M2OM; K2C1; ADDG; MGP; COL12; MARE2; } \\
\text { DTNB; K2C4; MCAT; SPTN2; ADDA; MYO1B; MPCP }\end{array}$ \\
\hline $\begin{array}{l}\text { transporter } \\
\text { activity } \\
(\mathrm{GO}: 0005215)\end{array}$ & 4 & CGRE1; VATF; PCOC1; AT1B1 & 7 & VDAC2; PLS3; SFXN3; VDAC3; ABCD3; APOE; CXA1 \\
\hline $\begin{array}{l}\text { receptor activity } \\
\text { (GO:0004872) }\end{array}$ & 3 & LYOX; PCOC1; MCTS1 & 4 & NTRI; ANTR1; MEP50; TPBG \\
\hline $\begin{array}{l}\text { translation } \\
\text { regulator activity } \\
(\mathrm{GO}: 0045182)\end{array}$ & 1 & EI2BG & 2 & PDCD4; BZW2 \\
\hline $\begin{array}{c}\text { antioxidant } \\
\text { activity }\end{array}$ & 0 & & 1 & CATA \\
\hline
\end{tabular}


Table S4. GO analysis of differential proteins performed in PANTHER and classified based on biological process

\begin{tabular}{|c|c|c|c|c|}
\hline $\begin{array}{l}\text { biological } \\
\text { process }\end{array}$ & & Up-regulation proteins & & Down-regulation proteins \\
\hline $\begin{array}{l}\text { cellular process } \\
\text { (GO:0009987) }\end{array}$ & 51 & $\begin{array}{l}\text { GNL3; RL11; LYOX; RS11; RB27A; FPPS; FGF2; VATF; } \\
\text { PDIA1; PCOC1; PZRN3; RS28; ARHG6; ARHG6; RS16; } \\
\text { LYPA2; RS16; LYPA2; GRB10; RS27; S10AB; SERB; } \\
\text { SCMC2; RS17; TPM2; RAB1A; RS18; RL23A; PDXK; } \\
\text { SUMO2; ORN; RL36; RHOA; RL26; GFPT2; CYR61; } \\
\text { MCTS1; MAGI3; RS19; SDC2; OLR1; ARFG1; CHSP1; } \\
\text { PHF5A; RS13; ATIF1; SUMO3; RN181; IPP2; RL35A; YKT6; } \\
\text { EMC3; GSH0; GNL3 }\end{array}$ & 42 & $\begin{array}{l}\text { TBCE; KIF1B; SMC1A; MRCKA; CAV1; M2OM; BST1; } \\
\text { CATL1; PLS3; NTRI; CATA; SLIT3; K2C1; RPN2; CTHR1; } \\
\text { LPP3; COL12; MARE2; DTNB; H2AY; K2C4; SQSTM; } \\
\text { RASA1; LPP1; MEP50; MCAT; SPTN2; IBP5; TPBG; AAK1; } \\
\text { C2D1A; APOE; H4; MYO1B; HXK1; CXA1; MPCP; NT5D2; } \\
\text { SLIT2; WNT5A; PLXA3 }\end{array}$ \\
\hline $\begin{array}{l}\text { metabolic } \\
\text { process } \\
(\mathrm{GO}: 0008152)\end{array}$ & 50 & $\begin{array}{l}\text { PDCL3; RL11; LYOX; RS11; CGL; FPPS; CRIP2; TBCA; } \\
\text { VATF; SSRA; PCOC1; PAIRB; PPME1; RS16; RL10A; } \\
\text { LYPA2; RS27; S10AB; SERB; SCMC2; PURB; RS17; RS18; } \\
\text { RL23A; PDXK; SUMO2; ARSB; ORN; EI2BG; RL36; } \\
\text { LRRF1; HIBCH; CK5P3; RL26; GFPT2; THRB; PA24A; } \\
\text { CYBP; CHSP1; PHF5A; ADAS; RS13; ATIF1; SUMO3; } \\
\text { RN181; IPP2; RL35A; EMC3; GSH0; GNL3 }\end{array}$ & 29 & $\begin{array}{l}\text { KIF1B; SMC1A; THTM; CAV1; M2OM; CATL1; CATA; } \\
\text { RPN2; LPP3; DHI1; H2AY; PSME2; SQSTM; RASA1; } \\
\text { ABCD3; COX7C; LPP1; MEP50; P85A; MCAT; }\end{array}$ \\
\hline $\begin{array}{c}\text { cellular } \\
\text { component } \\
\text { organization or } \\
\text { biogenesis } \\
\text { (GO:0071840) }\end{array}$ & 16 & $\begin{array}{l}\text { RL11; CRIP2; PZRN3; RS28; RS16; RS27; RS17; TPM2; } \\
\text { RS18; RL23A; RL23A; RL26; RS19; SDC2; RL35A; YKT6; } \\
\text { GNL3 }\end{array}$ & 20 & $\begin{array}{l}\text { TBCE; SMC1A; PLS3; SLIT3; K2C1; ADDG; CTHR1; } \\
\text { COL12; MARE2; DTNB; H2AY; K2C4; MEP50; AAK1; } \\
\text { ADDA; APOE; H4; MYO1B; SLIT2; PLXA3; }\end{array}$ \\
\hline $\begin{array}{l}\text { multicellular } \\
\text { organismal } \\
\text { process }\end{array}$ & 15 & $\begin{array}{c}\text { CO2A1; PCOC1; PZRN3; ARHG6; COBA1; TPM2; CO3A1; } \\
\text { SFTPA; MAGI3; HBB1; CO5A1; SDC2; HBA; CO1A1; } \\
\text { CO1A2 }\end{array}$ & 7 & SLIT3; ADA10; APOE; MYO1B; SLIT2; WNT5A; PLXA3 \\
\hline
\end{tabular}




\begin{tabular}{|c|c|c|c|c|}
\hline (GO:0032501) & & & & \\
\hline $\begin{array}{l}\text { localization } \\
\text { (GO:0051179) }\end{array}$ & 14 & $\begin{array}{l}\text { LYOX; RB27A; PICAL; CGRE1; VATF; SSRA; PCOC1; } \\
\text { RS28; RAB1A; RHOA; HBB1; SDC2; YKT6; HBA }\end{array}$ & 14 & $\begin{array}{l}\text { KIF1B; THTM; CAV1; VDAC2; PLS3; ALBU; TMED2; } \\
\text { VDAC3; ABCD3; MEP50; AAK1; APOE; MYO1B; PLXA3 }\end{array}$ \\
\hline $\begin{array}{l}\text { developmental } \\
\text { process } \\
(\mathrm{GO}: 0032502)\end{array}$ & 13 & $\begin{array}{c}\text { CO2A1; GMFB; FGF2; CRIP2; PDIA1; PCOC1; PZRN3; } \\
\text { COBA1; TPM2; CYR61; SDC2; CO1A2 }\end{array}$ & 12 & $\begin{array}{l}\text { MRCKA; NTRI; SLIT3; PDCD4; ADA10; COL12; SPTN2; } \\
\text { APOE; MYO1B; SLIT2; WNT5A; PLXA3 }\end{array}$ \\
\hline $\begin{array}{l}\text { immune system } \\
\text { process } \\
(\mathrm{GO}: 0002376)\end{array}$ & 12 & $\begin{array}{l}\text { LYOX; CRIP2; PCOC1; ARHG6; COBA1; S10AB; CO3A1; } \\
\text { SFTPA; CO5A1; PA24A; OLR1; CO1A1 }\end{array}$ & 4 & BST1; COL12; PSME2; GLO2 \\
\hline $\begin{array}{l}\text { biological } \\
\text { regulation } \\
(\mathrm{GO}: 0065007)\end{array}$ & 9 & $\begin{array}{l}\text { LYOX; RB27A; CRIP2; PDIA1; CK5P3; SFTPA; CYR61; } \\
\text { PAI1; GSH0 }\end{array}$ & 14 & $\begin{array}{c}\text { BST1; PLS3; LPP3; H2AY; PSME2; SQSTM; LPP1; IBP5; } \\
\text { AAK1; APOE; HXK1; SLIT2; WNT5A; PLXA3 }\end{array}$ \\
\hline $\begin{array}{l}\text { response to } \\
\text { stimulus } \\
\text { (GO:0050896) }\end{array}$ & 7 & CGRE1; CRIP2; PDIA1; PCOC1; ARHG6; CYR61; THRB & 15 & $\begin{array}{c}\text { THTM; CATA; LPP3; PSME2; SQSTM; RASA1; LPP1; } \\
\text { P85A; GLO2; IBP5; AAK1; APOE; SLIT2; WNT5A; PLXA3 }\end{array}$ \\
\hline $\begin{array}{l}\text { biological } \\
\text { adhesion } \\
\text { (GO:0022610) }\end{array}$ & 4 & LYOX; PCOC1; PLOD2; CYR61 & 2 & CTHR1; COL12 \\
\hline $\begin{array}{l}\text { locomotion } \\
(\mathrm{GO}: 0040011)\end{array}$ & 1 & SDC2 & 2 & SLIT2; PLXA3 \\
\hline $\begin{array}{l}\text { reproduction } \\
(\mathrm{GO}: 0000003)\end{array}$ & 1 & CRIP2 & 1 & ADA10 \\
\hline
\end{tabular}


Table S5. GO analysis of differential proteins performed in PANTHER and classified based on cellular component

\begin{tabular}{|c|c|c|c|c|}
\hline $\begin{array}{c}\text { cellular } \\
\text { component }\end{array}$ & & Up-regulation proteins & & Down-regulation proteins \\
\hline $\begin{array}{c}\text { cell part } \\
(\mathrm{GO}: 0044464)\end{array}$ & 43 & $\begin{array}{l}\text { PDCL3; RL11; RS11; RB27A; PICAL; FPPS; CRIP2; RS20; } \\
\text { RS12; NOLC1; RS28; RS16; FA98A; FA98A; LYPA2; RS27; } \\
\text { SERB; RS17; TPM2; RAB1A; RS18; RL36A; RL23A; PDXK; } \\
\text { SUMO2; RL36; CK5P3; RL26; METK2; RS19; SDC2; } \\
\text { PA24A; TCTP; PHF5A; RS13; ATIF1; SUMO3; IPP2; RL35A; } \\
\text { YKT6; EMC3; GSH0; RS3A; GNL3 }\end{array}$ & 23 & $\begin{array}{l}\text { KIF1B; CATL1; CATA; K2C1; RPN2; RM37; ADDG; CN37; } \\
\text { MARE2; DTNB; TMED2; H2AY; K2C4; PSME2; SQSTM; } \\
\text { RASA1; P85A; SPTN2; AAK1; ADDA; C2D1A; MYO1B; } \\
\text { HXK1 }\end{array}$ \\
\hline $\begin{array}{c}\text { organelle } \\
\text { (GO:0043226) }\end{array}$ & 26 & $\begin{array}{l}\text { RL11; RS11; RB27A; RS20; RS12; NOLC1; RS28; RS16; } \\
\text { RS27; RS17; RAB1A; RS18; RL36A; RL23A; SUMO2; RL36; } \\
\text { RL26; RS19; TCTP; PHF5A; RS13; ATIF1; SUMO3; RL35A; } \\
\text { EMC3; GNL3 }\end{array}$ & 15 & $\begin{array}{c}\text { KIF1B; CATL1; K2C1; RPN2; RM37; ADDG; MARE2; } \\
\text { DTNB; H2AY; K2C4; PSME2; SQSTM; ADDA; C2D1A; } \\
\text { MYO1B }\end{array}$ \\
\hline $\begin{array}{l}\text { macromolecular } \\
\text { complex } \\
(\mathrm{GO}: 0032991)\end{array}$ & 24 & $\begin{array}{l}\text { RL11; RS11; PICAL; RS20; RS12; RS28; RS16; FA98A; } \\
\text { RS27; RS17; RS18; RL36A; RL23A; RL36; RL26; METK2; } \\
\text { RS19; PHF5A; RS13; IPP2; RL35A; YKT6; EMC3; GSH0 }\end{array}$ & 6 & KIF1B; RPN2; TMED2; PSME2; P85A; APOE \\
\hline $\begin{array}{c}\text { membrane } \\
(\mathrm{GO}: 0016020)\end{array}$ & 4 & RAB1A; MAGI3; YKT6; EMC3 & 8 & BST1; PLS3; RPN2; LPP3; RASA1; LPP1; MYO1B; CXA1 \\
\hline $\begin{array}{l}\text { extracellular } \\
\text { region } \\
(\mathrm{GO}: 0005576)\end{array}$ & 3 & PCOC1; CYR61; PAI1 & 6 & CATL1; COL12; IBP5; TPBG; APOE; WNT5A \\
\hline $\begin{array}{l}\text { extracellular } \\
\text { matrix } \\
(\mathrm{GO}: 0031012)\end{array}$ & 2 & PCOC1; CYR61 & & MMP2; CTHR1; COL12 \\
\hline $\begin{array}{l}\text { cell junction } \\
\text { (GO:0030054) }\end{array}$ & 1 & MAGI3 & 1 & MYO1B \\
\hline $\begin{array}{c}\text { synapse } \\
(\mathrm{GO}: 0045202)\end{array}$ & 1 & PZRN3 & 0 & \\
\hline
\end{tabular}


Table S6. Protein class ontology analysis of differential proteins performed in PANTHER

\begin{tabular}{|c|c|c|c|c|}
\hline protein class & & Up-regulation proteins & & Down-regulation proteins \\
\hline $\begin{array}{l}\text { nucleic acid } \\
\text { binding } \\
(\mathrm{PC} 00171)\end{array}$ & 29 & $\begin{array}{c}\text { RL11; RS11; CRIP2; RS20; RS12; PAIRB; RS28; RS16; } \\
\text { RL10A; RS27; SCMC2; PURB; RS17; RS18; RL36A; RL23A; } \\
\text { ORN; EI2BG; RL36; LRRF1; RL26; RS24; RS19; ARFG1; } \\
\text { CHSP1; RS13; RL35A; RS3A; GNL3 }\end{array}$ & 9 & $\begin{array}{l}\text { SMC1A; M2OM; PDCD4; UBF1; H2AY; MCAT; BZW2; H4; } \\
\text { MPCP }\end{array}$ \\
\hline $\begin{array}{l}\text { hydrolase } \\
(\text { PC00121) }\end{array}$ & 12 & $\begin{array}{l}\text { LYOX; PCOC1; VCAM1; PPME1; LYPA2; SERB; ARSB; } \\
\text { ORN; 2AAB; THRB; PA24A; GNL3; }\end{array}$ & 9 & $\begin{array}{l}\text { SMC1A; BST1; CATL1; CN37; LPP3; LPP1; GLO2; CNTN2; } \\
\text { NT5D2 }\end{array}$ \\
\hline $\begin{array}{l}\text { enzyme } \\
\text { modulator } \\
(\mathrm{PC} 00095)\end{array}$ & 11 & $\begin{array}{c}\text { PDCL3; GMFB; PCOC1; ARHG6; EI2BG; RHOA; FSTL1; } \\
\text { PAI1; ARFG1; IPP2; GNL3 }\end{array}$ & 4 & CAV1; RASA1; P85A; MYO1B \\
\hline $\begin{array}{l}\text { signalling } \\
\text { molecule } \\
(\mathrm{PC} 00207)\end{array}$ & 9 & $\begin{array}{l}\text { GMFB; FGF2; PCOC1; ARHG6; S10AB; CYR61; SDC2; } \\
\text { OLR1; GNL3 }\end{array}$ & 4 & MGP; UBF1; WNT5A; PLXA3 \\
\hline $\begin{array}{l}\text { transferase } \\
(\mathrm{PC} 00220)\end{array}$ & 8 & $\begin{array}{l}\text { TANC1; FPPS; PDXK; EI2BG; HIBCH; METK2; GFPT2; } \\
\text { MAGI3 }\end{array}$ & 6 & THTM; MRCKA; RPN2; MAGT1; AAK1; HMGCL \\
\hline $\begin{array}{l}\text { oxidoreductase } \\
\quad(\mathrm{PC} 00176)\end{array}$ & 6 & LYOX; PCOC1; ERG; HIBCH; DYR; ADAS & 5 & AL3A1; CATA; CTHR1; DHI1; COX7C \\
\hline $\begin{array}{l}\text { receptor } \\
(\mathrm{PC} 00197)\end{array}$ & 5 & LYOX; PCOC1; VCAM1; MCTS1; VLDLR & 6 & NTRI; ANTR1; MEP50; TPBG; CNTN2; PLXA3 \\
\hline $\begin{array}{l}\text { cytoskeletal } \\
\text { protein } \\
(\mathrm{PC} 00085)\end{array}$ & 4 & CRIP2; TPM2; SDC2; TCTP & 9 & $\begin{array}{c}\text { KIF1B; K2C1; ADDG; MARE2; DTNB; K2C4; SPTN2; } \\
\text { ADDA; MYO1B }\end{array}$ \\
\hline ligase (PC00142) & 4 & HIBCH; CYBP; ATIF1; GSH0 & 0 & \\
\hline $\begin{array}{l}\text { transfer/carrier } \\
\text { protein } \\
(\mathrm{PC} 00219)\end{array}$ & 4 & PCOC1; SCMC2; HBB1; HBA & 8 & $\begin{array}{l}\text { THTM; M2OM; PLS3; ALBU; SFXN3; TMED2; MCAT; } \\
\text { MPCP }\end{array}$ \\
\hline $\begin{array}{l}\text { transporter } \\
(\mathrm{PC} 00227)\end{array}$ & 4 & CGRE1; PCOC1; SCMC2; AT1B1 & 7 & M2OM; VDAC2; SFXN3; VDAC3; ABCD3; MCAT; MPCP \\
\hline $\begin{array}{l}\text { calcium-binding } \\
\text { protein } \\
(\mathrm{PC} 00060)\end{array}$ & 3 & SSRA; S10AB; SCMC2 & 4 & M2OM; MGP; MCAT; MPCP \\
\hline
\end{tabular}




\begin{tabular}{|c|c|c|c|c|}
\hline $\begin{array}{l}\text { cell adhesion } \\
\text { molecule } \\
\text { (PC00069) }\end{array}$ & 3 & PCOC1; VCAM1; SDC2 & 1 & CNTN2 \\
\hline $\begin{array}{c}\text { defence/immunity } \\
\text { protein } \\
\text { (PC00090) }\end{array}$ & 3 & VCAM1; SFTPA; SDC2 & 1 & CNTN2 \\
\hline $\begin{array}{l}\text { extracellular } \\
\text { matrix protein } \\
\text { (PC00102) }\end{array}$ & 3 & PCOC1; SDC2; VLDLR & 3 & MGP; COL12; TPBG \\
\hline $\begin{array}{c}\text { membrane traffic } \\
\text { protein } \\
\text { (PC00150) }\end{array}$ & 3 & PICAL; SSRA; YKT6 & 2 & CAV1; TMED2 \\
\hline $\begin{array}{c}\text { transcription } \\
\text { factor (PC00218) }\end{array}$ & 3 & CRIP2; PURB; LRRF1 & 1 & UBF1 \\
\hline $\begin{array}{l}\text { chaperone } \\
\text { (PC00072) }\end{array}$ & 2 & PDCL3; TBCA & 1 & TBCE \\
\hline lyase (PC00144) & 2 & CGL; HIBCH & 2 & BST1; HMGCL \\
\hline $\begin{array}{c}\text { cell junction } \\
\text { protein } \\
\text { (PC00070) }\end{array}$ & 1 & MAGI3 & 2 & MYO1B; CXA1 \\
\hline $\begin{array}{l}\text { transmembrane } \\
\text { receptor } \\
\text { regulatory/adaptor } \\
\text { protein } \\
\text { (PC00226) }\end{array}$ & 1 & GRB10 & 1 & CAV1 \\
\hline $\begin{array}{l}\text { structural protein } \\
\text { (PC00211) }\end{array}$ & 0 & & 4 & CAV1; K2C1; MGP; K2C4 \\
\hline
\end{tabular}


Table S7. Pathway analysis of differential proteins performed in PANTHER

\begin{tabular}{|c|c|c|c|c|}
\hline Pathway analysis & & -regulation proteins & Down-regul & tion proteins \\
\hline Integrin signalling pathway (P00034) & 8 & $\begin{array}{l}\text { CO2A1; COBA1; CO3A1; RHOA; CO5A1; } \\
\text { ARFG1; CO1A1; CO1A2 }\end{array}$ & 2 & CAV1; P85A \\
\hline Angiogenesis (P00005) & 4 & FGF2; PAR1; RHOA; PA24A & 3 & $\begin{array}{l}\text { RASA1; P85A; } \\
\text { WNT5A }\end{array}$ \\
\hline Blood coagulation (P00011) & 3 & PAR1; THRB; PAI1 & 0 & \\
\hline CCKR signalling map (P06959) & 3 & RHOA; PAI1; PA24A & 1 & P85A \\
\hline Cholesterol biosynthesis (P00014) & 3 & FPPS; FDFT; ERG1 & 0 & \\
\hline p53 pathway (P00059) & 3 & SUMO2; PAI1; SUMO3 & 1 & P85A \\
\hline FGF signalling pathway (P00021) & 2 & FGF2; 2AAB & 1 & RASA1 \\
\hline Gonadotropin-releasing hormone receptor pathway (P06664) & 2 & GTR1; PA24A & 2 & CAV1; P85A \\
\hline $\begin{array}{l}\text { Inflammation mediated by chemokine and cytokine signalling pathway } \\
\text { (P00031) }\end{array}$ & & RHOA; PA24A & 0 & \\
\hline Alzheimer disease-presenilin pathway (P00004) & 1 & FSTL1 & 2 & MMP2; WNT5A \\
\hline $\begin{array}{l}\text { Angiotensin II-stimulated signalling through } \mathrm{G} \text { proteins and beta-arrestin } \\
\text { (P05911) }\end{array}$ & 1 & RHOA & 0 & \\
\hline Apoptosis signalling pathway (P00006) & 1 & GRP78 & 0 & \\
\hline Axon guidance mediated by semaphorins (P00007) & 1 & RHOA & 0 & \\
\hline Cadherin signalling pathway (P00012) & 1 & FSTL1 & 2 & CSK21; WNT5A \\
\hline Endothelin signalling pathway (P00019) & 1 & PA24A & 1 & P85A \\
\hline Formyltetrahydroformate biosynthesis (P02743) & 1 & DYR & 0 & \\
\hline $\begin{array}{l}\text { Heterotrimeric G-protein signalling pathway-Gq alpha and Go alpha } \\
\text { mediated pathway (P00027) }\end{array}$ & & RHOA & 0 & \\
\hline
\end{tabular}


Methionine biosynthesis (P02753)

1 CGL 0

N-acetylglucosamine metabolism (P02756)

$\mathrm{O}$-antigen biosynthesis (P02757)

1 GFPT2

0

Oxidative stress response (P00046)

1 GFPT2

Parkinson disease (P00049)

1 PA24A 0

Plasminogen activating cascade (P00050)

1 GRP78

\section{CSK21}

Pyridoxal phosphate salvage pathway (P02770)

1 PAI1

Ras Pathway (P04393)

S-adenosylmethionine biosynthesis (P02773)

1 PDXK

0

Serine glycine biosynthesis (P02776)

Tetrahydrofolate biosynthesis (P02742)

1 RHOA 0

1 METK2 0

1 SERB 0

1 DYR 0

VEGF signalling pathway (P00056)

1 PA24A 1

Vitamin B6 metabolism (P02787)

Wnt signalling pathway (P00057)

5-Hydroxytryptamine degradation (P04372)

1 PDXK

P85A

(2)

Alzheimer disease-amyloid secretase pathway (P00003)

Axon guidance mediated by Slit/Robo (P00008)

Axon guidance mediated by netrin (P00009)

Cell cycle (P00013)

EGF receptor signalling pathway (P00018)

Fructose galactose metabolism (P02744)

FSTL1 0

0

General transcription by RNA polymerase I (P00022)

Glycolysis (P00024)

Hypoxia response via HIF activation (P00030)

0

Insulin/IGF pathway-mitogen activated protein kinase kinase/MAP kinase

cascade (P00032)

0

AL3A1

1 ADA10

2 SLIT3; SLIT2

$\begin{array}{lll}0 & 1 & \text { P85A } \\ 0 & 1 & \text { PSME2 }\end{array}$

$0 \quad 1$ RASA1

$0 \quad 1$ HXK1

$0 \quad 1$ UBF1

$0 \quad 1$ HXK1

$\begin{array}{lll}0 & 1 & \text { P85A }\end{array}$

1 RASA1 


\begin{tabular}{|c|c|c|c|}
\hline Insulin/IGF pathway-protein kinase B signalling cascade (P00033) & 0 & 1 & P85A \\
\hline Nicotinic acetylcholine receptor signalling pathway (P00044) & 0 & 1 & MYO1B \\
\hline Notch signalling pathway (P00045) & 0 & 1 & ADA10 \\
\hline PDGF signalling pathway (P00047) & 0 & 2 & RASA1; P85A \\
\hline PI3 kinase pathway (P00048) & 0 & 1 & P85A \\
\hline Pentose phosphate pathway (P02762) & 0 & 1 & HXK1 \\
\hline $\mathrm{T}$ cell activation $(\mathrm{P} 00053)$ & 0 & 1 & P85A \\
\hline VEGF signalling pathway (P00056) & 0 & 1 & P85A \\
\hline Wnt signalling pathway (P00057) & 0 & 2 & CSK21; WNT5A \\
\hline p53 pathway feedback loops 2 (P04398) & 0 & 1 & P85A \\
\hline
\end{tabular}

